\title{
Article \\ NOV/CCN3 Promotes Cell Migration and Invasion in Intrahepatic Cholangiocarcinoma via miR-92a-3p
}

\author{
Tingming Liang ${ }^{1}{ }^{\mathbb{D}}$, Lulu Shen ${ }^{1}$, Yaya $\mathrm{Ji}^{1}{ }^{1}$, Lin Jia ${ }^{1}$, Yuyang Dou ${ }^{2}$ and Li Guo ${ }^{2, *}$ \\ 1 Jiangsu Key Laboratory for Molecular and Medical Biotechnology, School of Life Science, \\ Nanjing Normal University, Nanjing 210023, China; tmliang@njnu.edu.cn (T.L.); \\ 191202064@stu.njnu.edu.cn (L.S.); 171202083@stu.njnu.edu.cn (Y.J.); 201202100@njnu.edu.cn (L.J.) \\ 2 Department of Bioinformatics, Smart Health Big Data Analysis and Location Services Engineering Lab of \\ Jiangsu Province, School of Geographic and Biologic Information, Nanjing University of Posts \\ and Telecommunications, Nanjing 210023, China; 1020173016@njupt.edu.cn \\ * Correspondence: lguo@njupt.edu.cn
}

Citation: Liang, T.; Shen, L.; Ji, Y.; Jia, L.; Dou, Y.; Guo, L. NOV/CCN3

Promotes Cell Migration and Invasion in Intrahepatic Cholangiocarcinoma via miR-92a-3p. Genes 2021, 12, 1659. https://doi.org/ 10.3390 /genes12111659

Academic Editor: Kumiko Ui-Tei

Received: 26 September 2021

Accepted: 20 October 2021

Published: 21 October 2021

Publisher's Note: MDPI stays neutral with regard to jurisdictional claims in published maps and institutional affiliations.

Copyright: (c) 2021 by the authors. Licensee MDPI, Basel, Switzerland. This article is an open access article distributed under the terms and conditions of the Creative Commons Attribution (CC BY) license (https:// creativecommons.org/licenses/by/ $4.0 /)$.

\begin{abstract}
Intrahepatic cholangiocarcinoma (ICC) is a common type of human cancer with a poor prognosis, and investigating the potential molecular mechanisms that can contribute to gene diagnosis and therapy. Herein, based on the recently concerned vertebrate-specific Cyr61/CTGF/NOV $(\mathrm{CCN})$ gene family because of its important roles in diverse diseases, we obtained NOV/CCN3 to query for its potential roles in tumorigenesis via bioinformatics analysis. Experimental validations confirmed that both NOV mRNA and protein are up-regulated in two ICC cell lines, suggesting that it may promote cell migration and invasion by promoting EMT. To elucidate the detailed regulatory mechanism, miR-92a-3p is screened and identified as a negative regulatory small RNA targeting NOV, and further experimental validation demonstrates that miR-92a-3p contributes to NOV-mediated migration and invasion of ICC via the Notch signaling pathway. Our study reveals that NOV may be a potential target for diagnosing and treating ICC, which will provide experimental data and molecular theoretical foundation for cancer treatment, particularly for future precision medicine.
\end{abstract}

Keywords: NOV/CCN3; miR-92a-3p; cell migration; invasion; intrahepatic cholangiocarcinoma

\section{Introduction}

Intrahepatic cholangiocarcinoma (ICC), a refractory liver malignancy, is one of the most common cancers, and patients diagnosed with ICC are challenging to cure with poor prognosis [1]. The median survival time of patients is less than 24 months [2]. Only $15 \%$ of patients are identified as a resectable disease [3] because it is difficult to obtain an early diagnosis, which mainly derives from asymptomatic or non-specific clinical symptoms [4]. Currently, surgical resection is still the only method to cure this disease, but only $30-60 \%$ of patients are candidates due to locally advanced or metastatic disease or frailty [5]. Following surgical resection, the median survival time is 25 months, and the 5-year survival is $20-40 \%$ [5]. It is critical to screen potential molecular markers for predicting therapeutic responses that would further contribute to studying molecular mechanisms underlying ICC, particularly for its effective management.

Many studies have revealed that some abnormally expressed genes have crucial roles in the occurrence and development of ICC. For instance, eIF3C and KI67 may be valuable predictors of survival and recurrence of ICC patients [6], NR4A2/OPN/Wnt signaling axis may be a pivotal executor of hepatic stellate cells instigated cancer-promoting roles in ICC [7], typing FGFR2 translocation can determine the response to targeted therapy of intrahepatic cholangiocarcinoma [8], and DKK-1 combined with CA 19-9 may be the potential diagnostic and prognostic marker that may be better than CA 19-9 alone [9]. These studies strongly indicate that some key genes may be potential markers with diagnostic and prognostic values, implying their roles in cancer pathophysiology. Similarly, some 
genes have been validated as having potential roles in ICC development. Blockade of CXCL12/CXCR4 signaling can inhibit ICC progression and metastasis through inactivation of canonical Wnt pathway [10], lncRNA MT1JP has a protective role via regulating miR18a-5p/FBP1 axis [11], and crenigacestat, a selective NOTCH1 inhibitor, can reduce ICC progression via blocking VEGFA/DLL4/MMP13 axis [12]. The study that focuses on crucial genes in cancer will provide more important references by elucidating the detailed molecular mechanisms.

Numerous studies have found that the CCN gene family may also have potential roles in various diseases. Six homologous members have been identified, mainly including CCN1 (Cyr61), CCN2 (CTGF), CCN3 (NOV), CCN4 (WISP1), CCN5 (WISP2), and CCN6 (WISP3), which is only detected in vertebrates as a vertebrate-specific gene family [13]. They are implicated in the pathological processes of fibrosis [14], development [13], and inflammation [15]. This family has been validated with important roles in cancer progression [16-19]. CCN2 is a prognostic marker [20], and CDK/CCN and CDKI alterations may contribute to cancer prognosis and therapeutic predictivity [21]. CCN1 is identified as a tumor suppressor in non-small cell lung cancer [22], and it is also can be used to predict survival with endometrial cancer of endometrioid subtype [23]. Vitamin D-mediated regulation of CCN genes may be an adjuvant therapy for cancer and fibrosis [24], and CDK/CCN and CDKI alterations for cancer prognosis and therapeutic predictivity [21]. Although relevant studies have demonstrated the potential crucial roles of the $\mathrm{CCN}$ gene family in cancer, fewer studies have examined the detailed biological roles in ICC occurrence and development. Given the poor prognosis associated with ICC, it is quite necessary to understand and validate the potential biological roles of the $\mathrm{CCN}$ family to provide relevant references for precision treatment.

Herein, based on homologous members in the CCN gene family, we screened and verified abnormally expressed NOV (Nephrblastoma overexpressed, also known as CCN3) via pan-cancer analysis to perform further experimental validation. We found that NOV overexpression may be derived from miR-92a-3p regulation, contributing to NOV-mediated migration and metastasis of intrahepatic cholangiocarcinoma cells. Our study reveals that NOV is a potential target for pre-ICC diagnosis and treatment, providing experimental evidence and a molecular theoretical foundation for cancer treatment, particularly for future precision medicine.

\section{Materials and Methods}

\subsection{Data Resources}

We first analyzed expression patterns of the six homologous gene members in the CCN gene family for their expression patterns via a pan-cancer analysis using high-throughput sequencing data in the Cancer Genome Atlas (TCGA) (https:/ /tcga-data.nci.nih.gov/tcga/, accessed on 28 January 2021) with the "TCGAbiolinks" package [25] (http:/ / doi.org/10.109 $3 /$ nar / gkv1507, accessed on 28 January 2021). To screen candidate crucial genes associated with ICC, an integrative analysis was performed using Starbase [26] and GEPIA [27] databases. Differentially expressed genes were mainly analyzed using DESeq2 [28]. The genes were believed as abnormally expressed if $\mid \log _{2} \mathrm{FCl}>1.5$ and padj $<0.05$, or if $\left|\log _{2} \mathrm{FC}\right|>1.2$ and $p<0.05$ based on further paired analysis.

\subsection{Cell Culture and Grouping}

To further understand the biological function of screened genes, cell lines (HIBEC, human ICC HCCC-9810 and RBE), were purchased from Shanghai Institute of Cell Biology, Chinese Academy of Sciences (CAS; Shanghai, China). All cells were grown in RPMI-1640 medium containing $10 \%$ fetal bovine serum (FBS) (both obtained from Gibco, Grand Island, NY, USA), $100 \mu \mathrm{g} / \mathrm{mL}$ streptomycin and $100 \mathrm{U} / \mathrm{mL}$ penicillin (HyClone, Logan, UT, USA). The cells were stored in a $5 \% \mathrm{CO}_{2}$ atmosphere at $37^{\circ} \mathrm{C}$, and then were digested with $0.25 \%$ pancreatin-ethylene diamine tetraacetic acid and diluted in a ratio of 1:3 after reaching $80 \%$ confluency. 


\subsection{Construction of Plasmid and Transfection}

The full-length of NOV cDNA (Ensembl: ENSG00000136999) was cloned into pcDNA3.0 expression vector and then transfected into HCCC-9810 or RBE cells. The cells were seeded in six-well plates. When the fusion rate reached about $85 \%$, the cells were then transfected using NOV empty vector and overexpression vector respectively in line with Lipofectamine $^{\mathrm{TM}} 3000$ instructions (Thermo Fisher Scientific, Waltham, MA, USA). After $48 \mathrm{~h}$, the residual liquid in each well was replaced with DMEM 1640 complete medium. The cells were returned to the incubator at $37^{\circ} \mathrm{C}, 5 \% \mathrm{CO}_{2}$, and $95 \%$ humidity. After $48 \mathrm{~h}$, the transfected cells were used to determine the expression level of NOV using qRT-PCR and Western blot assays, respectively. Empty vector-transfected cells were used as controls.

\subsection{RNAi and Transfection}

Three designed NOV siRNAs and negative control siRNA were synthesized by Biotend, China. The sequences of siRNAs were as follows: $5^{\prime}$ GCACCAAGAAGUCACUCAAdTdT $3^{\prime}$ (sense) and 5' UUGAGUGACUUCUUGGUGCdTdT $3^{\prime}$ (antisense) for si-NOV-1, $5^{\prime}$ TAACTGCCCAGCTCCAAGAAdTdT $3^{\prime}$ (sense) and $5^{\prime}$ GAACCCCATACCACAGCTCTdTdT $3^{\prime}$ (antisense) for si-NOV-2, 5' GAGAUAACUGUGUGUUCGdTdT $3^{\prime}$ (sense) and $5^{\prime}$ UCGAACACACAGUUAUCUCdTdT $3^{\prime}$ (antisense) for si-NOV-3. The cells were cultured with six-well plates and then transfected with siRNAs using Lipofectamine 3000 (Thermo Fisher Scientific, Waltham, MA, USA) according to the manufacturer's protocol. After $48 \mathrm{~h}$, the cells were harvested for the subsequent experiments.

\subsection{Colony Formation Assay}

The ICC cells (HCCC 9810 and RBE) were suspended in RPMI-1640 medium with a final concentration of 500 cells per microliter and then seeded into six-well plates (Corning Inc., Corning, NY, USA). The culture medium (containing 10\% FBS) was replaced every three days. When a signal colony contained $>50$ cells, The cells were fixed and stained. Following that, the colony-forming units were stained with crystal violet and then photographed by microscope (Nikon Eclipse Ts2R; Nikon, Tokyo, Japan). The results were repeated in three independent experiments.

\subsection{Cell Viability Assay}

Cell viability test was performed in triplicate using a commercially available kit (Cell Counting Kit-8, CCK-8) (Tokyo, Japan). The cells were diluted to single-cell suspension and then seeded into 96-well plates $\left(1 \times 10^{3}\right.$ cells / well) with $100 \mu \mathrm{L}$ culture medium. After $12 \mathrm{~h}$ incubation, the cells were treated with siRNAs $(100 \mathrm{~nm})$ or NOV overexpression vector (1000 ng) for $48 \mathrm{~h}$. At the time point $(0,24,48,72$, and $96 \mathrm{~h})$, CCK-8 solution $(10 \mu \mathrm{L})$ was added to each well and incubated for $3 \mathrm{~h}$. The cell viability was calculated as absorbance of solutions that were detected at $450 \mathrm{~nm}$ with a microplate reader (Epoch, Biotech, Winooski, VT, USA). The results were represented as an average of five parallel samples. All related experiments were repeated at least three times.

\subsection{In Vitro Migration and Invasion Assays}

For wound-healing assay in vitro, cells (about $1 \times 10^{6}$ cells) were seeded into sixwell plates, and cells were incubated at $37{ }^{\circ} \mathrm{C}$ until reaching at least $90 \%$ confluence. Wounds were created via scratching cell monolayers using a $200 \mu \mathrm{L}$ plastic pipette tip, and then they were incubated in a fresh medium that contained $1 \%$ fetal calf serum. Cell migration into wound was monitored in a serum-free medium, which was photographed by a fluorescence microscope at 0 and $48 \mathrm{~h}$, respectively. Transwell filters ( $8 \mu \mathrm{m}$, Greiner Bio-One, Frickenhausen, Germany) were used to detect cell migration and invasion. HCCC$9810\left(1 \times 10^{5}\right)$ and RBE cells $\left(1 \times 10^{5}\right)$ in $200 \mu \mathrm{L}$ serum-free mediums were, respectively, added to the upper chamber containing an uncoated or Matrigel (Corning Life Sciences, Manassas, VA, USA)-coated membrane. The lower chamber was filled with $800 \mu \mathrm{L}$ basal medium containing $10 \% \mathrm{FBS}$. After $48 \mathrm{~h}$ of incubation at $37^{\circ} \mathrm{C}$ in a humidified $5 \% \mathrm{CO}_{2}$ 
incubator, the cells migrated to the lower compartment were fixed with methanol and then stained using crystal violet. Migrated or invaded cells were counted in three randomly chosen fields in each well. Imaging and cell counting were performed at $10 \times$ magnification with a fluorescence microscope. The relevant experiments were performed in triplicate.

\subsection{Quantitative Real-time RT-PCR}

Total RNAs of HIBEC, HCCC-9810, and RBE cells were extracted using TRIzol reagent (Invitrogen, Carlsbad, CA, USA). cDNA was then generated from the total RNAs using a reverse transcription kit (Takara, Dalian, China). Gene expression level was measured using an SYBR green kit (Yeasen, Shanghai, China) by q-PCR (Lightcycler96, Roche, Basel, Switzerland). Primers sequences of NOV (sense: $5^{\prime}$ TAACTGCCCAGCTCCAAGAA $3^{\prime}$, antisense: $5^{\prime}$ GAACCCCATACCACAGCTCT3'). GAPDH (sense: $5^{\prime}$ CGGAGTCAACGGATTTGGTCGTATTGG $3^{\prime}$, antisense: $5^{\prime}$ GCTCCTGGAAGATGGTGATGGGATTTCC $3^{\prime}$ ) and U6 snRNAs (5' CTCGCTTCGGCAGCACATATACT $3^{\prime}$, antisense: $5^{\prime}$ ACGCTTCACGAATTTGCGTGTC $3^{\prime}$ ) were used to normalize mRNA and miRNA levels, respectively. The expression of related genes was analyzed by the $2^{-\Delta \Delta \mathrm{Ct}}$ method (the control group was normalized).

\subsection{Western Blot Analysis}

HIBEC, HCCC-9810, and RBE cells were transfected with siRNAs (100 nm) or NOV overexpression vector (1000 ng) for $48 \mathrm{~h}$. Then the cells were harvested and lysed in RIPA buffer (Beyotime Institute of Biotechnology, Beijing, China) supplemented with protease inhibitor (Roche Applied Science, Indianapolis, IN, USA) at $4{ }^{\circ} \mathrm{C}$ for $15 \mathrm{~min}$. The cells were centrifuged with a microcentrifuge at $12,000 \times \mathrm{g}$ for $15 \mathrm{~min}$ at $4{ }^{\circ} \mathrm{C}$ to collect the supernatant. The protein concentration was then measured using bicinchoninic acid (BCA) assay kit (Beyotime). After boiling for $5 \mathrm{~min}$ in $1 \times$ SDS sample buffer, a total of $30 \mu \mathrm{g}$ of protein/lane was subjected to SDS-polyacrylamide gel electrophoresis (PAGE) and then electrophoretically transferred to polyvinylidene difluoride membranes (Millipore, Bedford, MA, USA). After blocking using 5\% skim milk for 1-2 h, the membranes were incubated with primary antibodies against Snail (1:1000), MMP9 (1:1000), vimentin (1:2000), $\mathrm{N}$-cadherin (1:10000), E-cadherin (1:4000), NOV (1:5000) and GAPDH (1:10000) at $4{ }^{\circ} \mathrm{C}$ overnight. After washing with Tris-buffered saline and Tween-20 (TBST) buffer three times ( 5 min per time), the blots were re-probed using secondary antibodies conjugated to horseradish peroxidase for 1 he. The protein bands were then observed using enhanced chemiluminescence and visualized with a Gel Doc 2000 (Bio-Rad, Hercules, CA, USA). Sch B and Rhodamine 123 (Rho 123) were obtained from Sigma-Aldrich (St. Louis, MO, USA). Sch B was dissolved in dimethyl sulfoxideto create a $100 \mathrm{~mm}$ stock solution. The control groups were treated with equal volumes of DMSO. Primary antibodies against Snail, MMP9, vimentin, N-cadherin, E-cadherin, GAPDH, and secondary antibodies (goat anti-rabbit) were all purchased from Proteintech (Wuhan, China). NOV antibody was purchased from Abcam (Cambridge, United Kingdom).

\subsection{Luciferase Reporter Construction}

A 3'-UTR region (1302 bp) of human NOV gene, containing a putative target site for miR-92a-3p, was identified from PITA (https://genie.weizmann.ac.il/pubs/mir07/ mir07_prediction.html, accessed on 18 March 2021), miRmap [29], miRanda [30] and TargetScan database [31] and amplified by PCR (miR-92a-3p primers: sense: $5^{\prime}$ GCGTATTGCACTTGTCCCG 3'; antisense: $5^{\prime}$ AGTGCAGGGTCCGAGGTATT 3'). The target fragment was used to insert between $\mathrm{XhoI}$ and NotI, in the pmiR-RB-Report ${ }^{\mathrm{TM}}$ vector. We also mutated $7 \mathrm{bp}$ of the miR-92-3p binding site from GTGCAAT to CACGTTA. Wildtype (WT) and mutant (Mut) insert sequences were confirmed and then transfected into HCCC-9810 cells. The cells were lysed, and supernatants were collected for further analysis. Relative luciferase activities were detected with commercial kits (E1910, Promega, Madison, 
WI, USA) and examined on a Luminoscan Ascent (Thermo Fisher Scientific, San Jose, CA, USA).

\subsection{Statistical Analysis}

Numeric data were presented as mean \pm standard deviation (SD) for multiple samples, and some methods were used to perform hypothesis testing in relevant analyses, mainly including Wilcoxon rank-sum test, paired $t$-test, a Student's $t$-test or one-way ANOVA analysis followed by Fisher's LSD post-hoc test, etc. All experiments were repeated at least three times. A $p$-value $<0.05$ was considered statistically significant. All analyses were performed using the R programming language (version 3.4.3).

\section{Results}

\subsection{Expression Patterns of CCN Family and Screening Crucial Genes in ICC}

To ascertain the potential expression patterns of the six members in the $\mathrm{CCN}$ gene family, expression analysis was performed in a variety of cancer types. A total of 18 cancer types were analyzed, and five genes were identified except for Cyr61. Most of them were abnormally expressed in different tissues (Figure 1A), especially for WISP2, which was down-regulated in 10 different tissues but up-regulated in KIRC. WISP1 was significantly up-regulated in eight tissues but down-regulated in UCEC. These dynamic expression patterns indicated that these homologous genes might have played important critical roles in cancer pathology, with the exception of NOV and WISP3, which had abnormal expression patterns in cholangiocarcinoma (also named CHOL in TCGA).

Despite the homology of these genes, which suggests a close association in biological processes, they demonstrated dynamic expression distributions in tumor and normal samples in ICC (Figure 1B). CTGF was the dominantly expressed gene, followed by NOV, whereas WISP3 and WISP2 had lower expression levels. To further understand the detailed expression patterns revealed by paired analysis, the two abnormally expressed genes were performed expression analysis across diverse cancer types (Figure 1C) using TCGA CHOL RNA sequencing data. Paired analysis revealed that NOV expression patterns were more deregulated in several cancers, while WISP3 expression patterns were more divergent than in total samples. Both analyses revealed that NOV and WISP3 were abnormally expressed in cholangiocarcinoma, but WISP3 was identified to be down-regulated and expressed at a lower level. Therefore, we finally screened NOV as a potential crucial gene associated with ICC to perform further experimental validation to ascertain its roles in biological processes, especially in the occurrence and development of cancer.

\subsection{Experimental Validation Shows High Expression of NOV}

Although the paired analysis indicated that the NOV gene could be deregulated in a variety of cancer types, significant expression patterns were detected only in BRCA (down-regulated) and CHOL (up-regulated) cancers (Figure 2A). The expression patterns implied its spatiotemporal expression across diverse tissues.

To further understand the detailed expression patterns in cells, we examined the expression levels of HCCC-9810 and RBE cells. Compared with BEC cells (normal human biliary epithelial cells), NOV mRNA in both HCCC-9810 and RBE cells were significantly up-regulated 15-fold $(p<0.001)$ and 23-fold $(p<0.001)$, respectively (Figure 2B). Simultaneously, NOV protein also revealed similar results (Figure 2C), indicating that NOV was also significantly overexpressed in cell lines and bioinformatics analysis. Numerous relevant studies have demonstrated that the potential roles of NOV in cancer. For instance, NOV may be an attractive target for therapeutic intervention in the alveolar subtype [32], and NOV may have a tumor-suppressive role in prostate cancer [33]. It is critical to elucidate the potential role of NOV in tumorigenesis. 

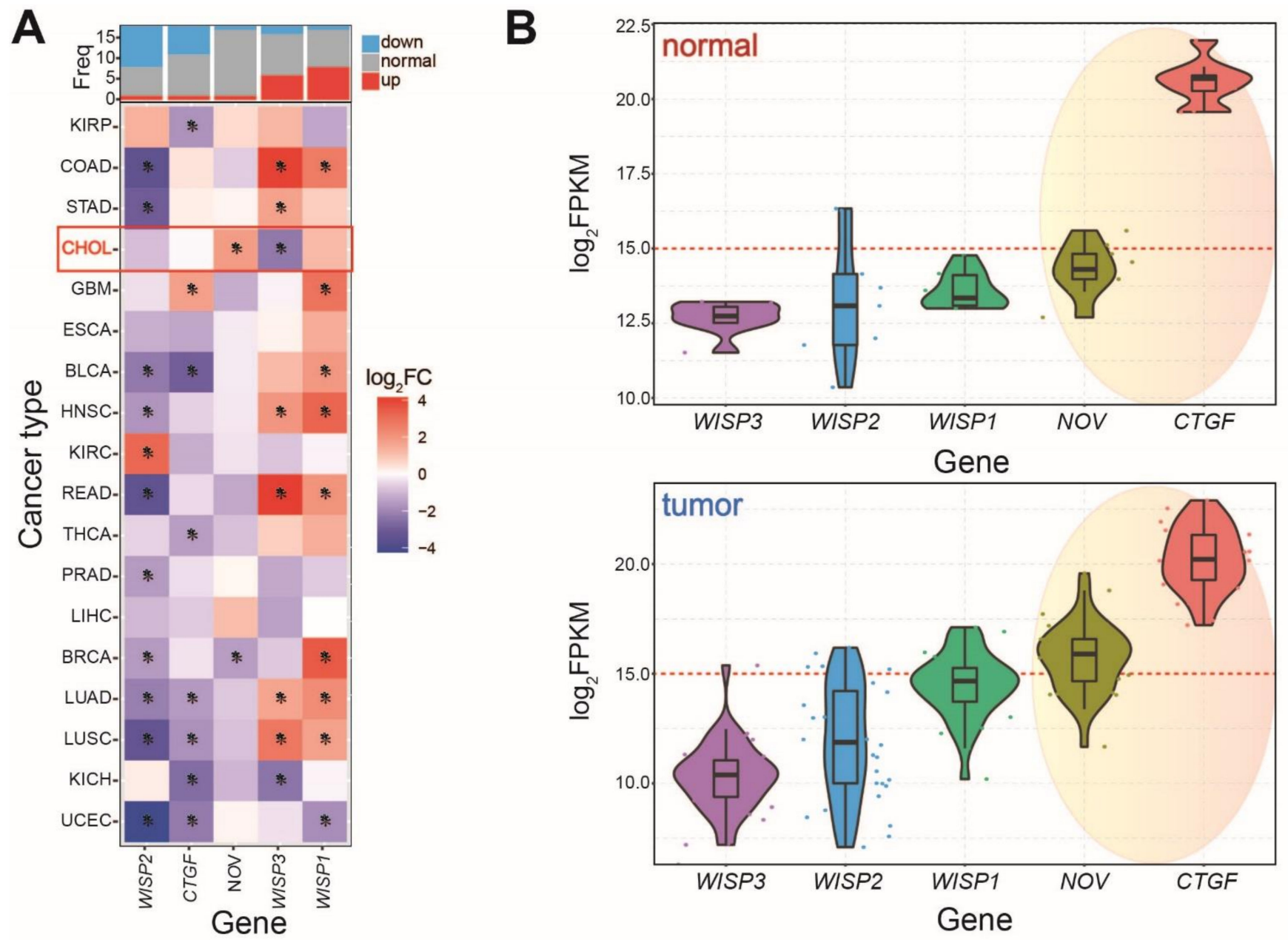

C

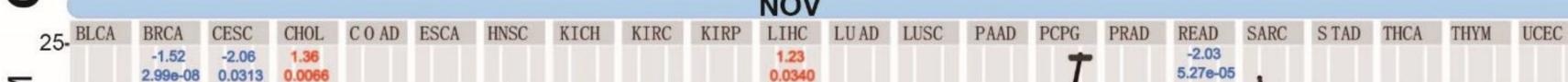

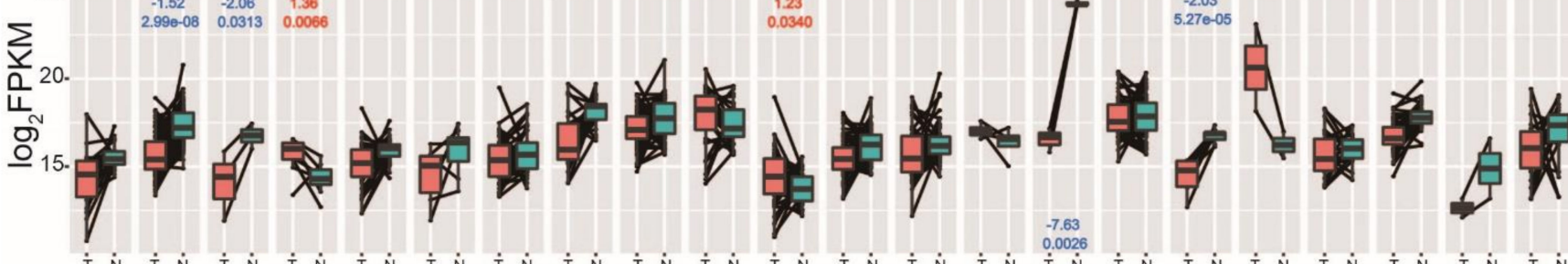

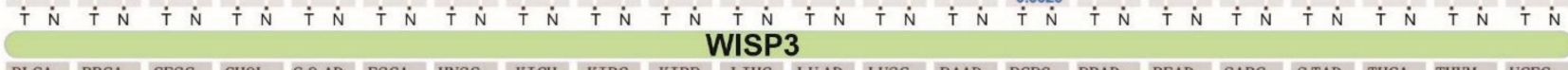

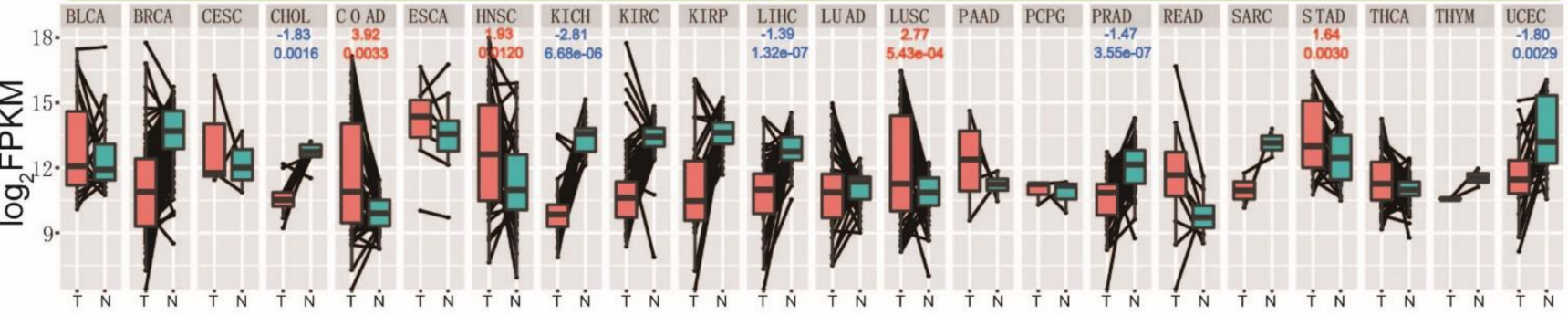

Figure 1. Pan-cancer analysis of expression pattern of CCN gene family. (A) Expression distributions of homologous genes in the CCN gene family. * indicates significantly deregulated genes $\left(\left|\log _{2} \mathrm{FC}\right|>1.5\right.$, padj < 0.05). (B) Expression patterns of five genes in normal and tumor samples in CHOL. (C) Paired analysis of deregulated NOV and WISP3 across diverse cancer types. The abnormally expressed genes are presented $\left(\mid \log _{2} \mathrm{FCl}>1.2\right.$, padj $<0.05$ for paired analysis). 


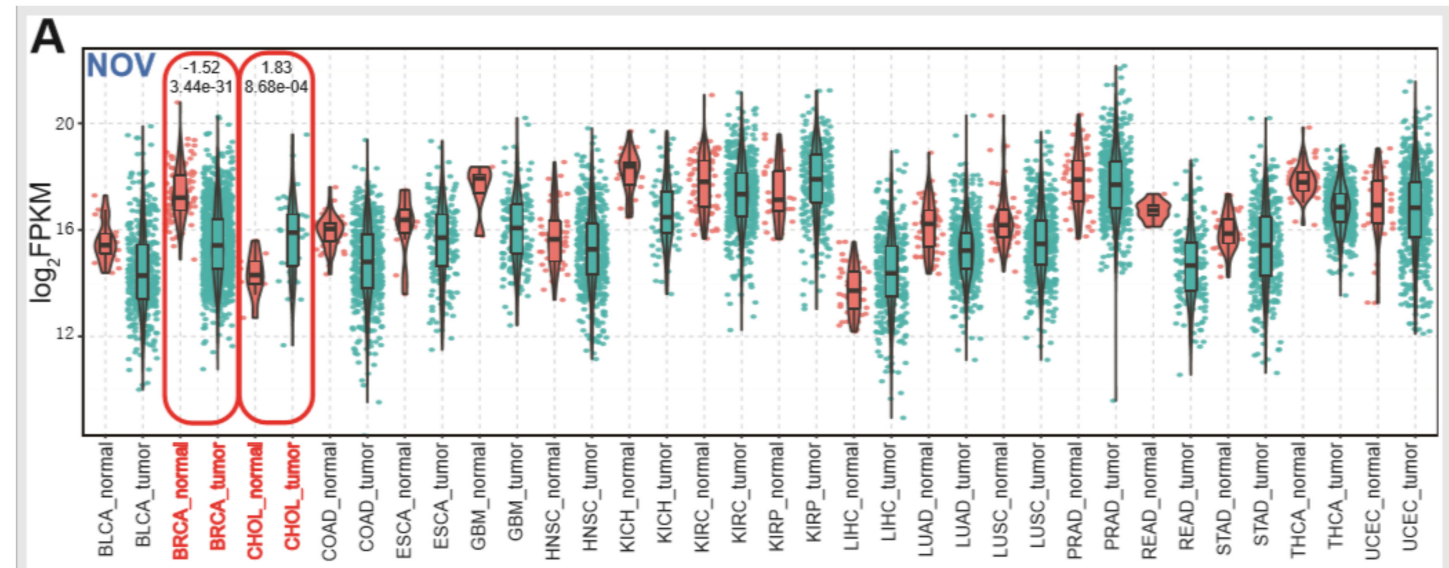

B

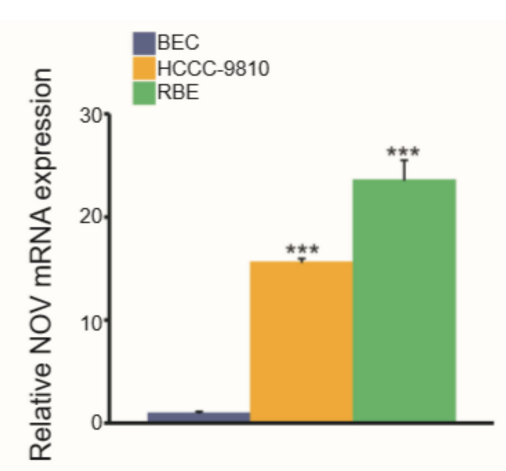

C

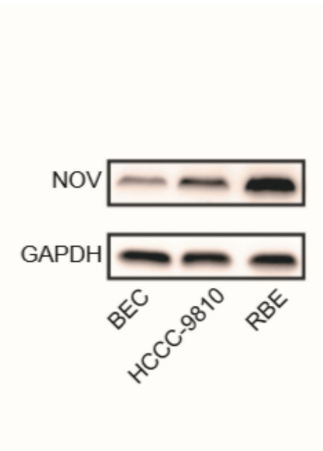

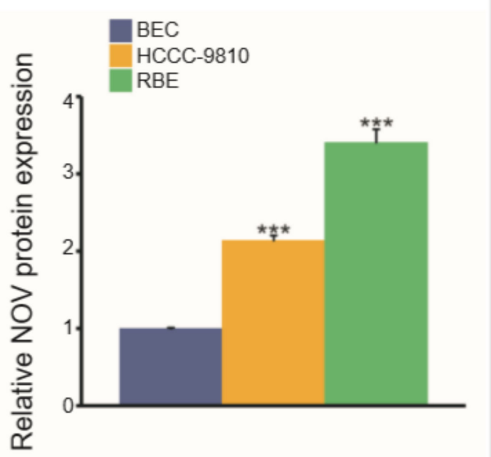

Figure 2. Expression analysis and experimental validation. (A) Pan-cancer analysis of screened NOV across cancer types based on tumor and normal samples. The red circled part means that there are significant difference on the expression of NOV in BRCA and CHOL (Tumor vs. Normal) (B) NOV mRNA expression based on the q-PCR method. ${ }^{* * *}$ indicates $p<0.001$. (C) NOV protein expression based on Western blot. ${ }^{* *}$ indicates $p<0.001$.

\subsection{NOV Is Involved in Cell Proliferation Process}

Transfection efficiency of NOV overexpression plasmid was validated in HCCC-9810 and RBE cells, respectively. The results indicated that relative expression levels of NOV mRNA were increased $(p<0.001)$, and NOV protein also demonstrated similar results $(p \leq 0.01)$ (Figure 3A,B). Concurrently, we also designed siRNA targeting NOV and NOV silencing to study the potential effect of NOV on cell proliferation. We finally selected si-NOV-1 and si-NOV-2 to perform additional functional validation (Figure 3C,D).

The multiplication rate of cell groups with NOV overexpression was greater than that in the negative control group at $96 \mathrm{~h}$ using CCK-8 assay, but no significant difference was detected than that in the control group (Figure 4A). Compared with the negative control group, multiplication rates of cell groups of si-NOV-1 and si-NOV-2 were reduced at $48 \mathrm{~h}$, but no significant difference was detected (Figure 4B). Similarly, colony formation assay showed that the number of colonies with overexpression and silence of NOV was not significantly increased or inhibited than that in the control group (Figure 4C,D). These findings indicated that NOV had no significant effect on the cell proliferation process in HCCC-9810 and RBE cells.

\subsection{NOV Promotes the Cell Migration and Invasion}

To understand the potential effect of NOV on cell migration ability, wound healing and transwell chamber assays were used to detect NOV overexpression and silencing. NOV overexpression may accelerate wound healing, indicating that NOV expression could increase cell migration ability (Figure 5A). On the other hand, NOV silencing could enlarge 
the wounding region in si-NOV-1 and si-NOV-2 groups, indicating a decreased ability of cells to migrate (Figure 5B). This was mainly derived from NOV silencing that might inhibit cell migration. These results implied that NOV promoted cell migration, which may be crucial in the occurrence and development of cancer.

A
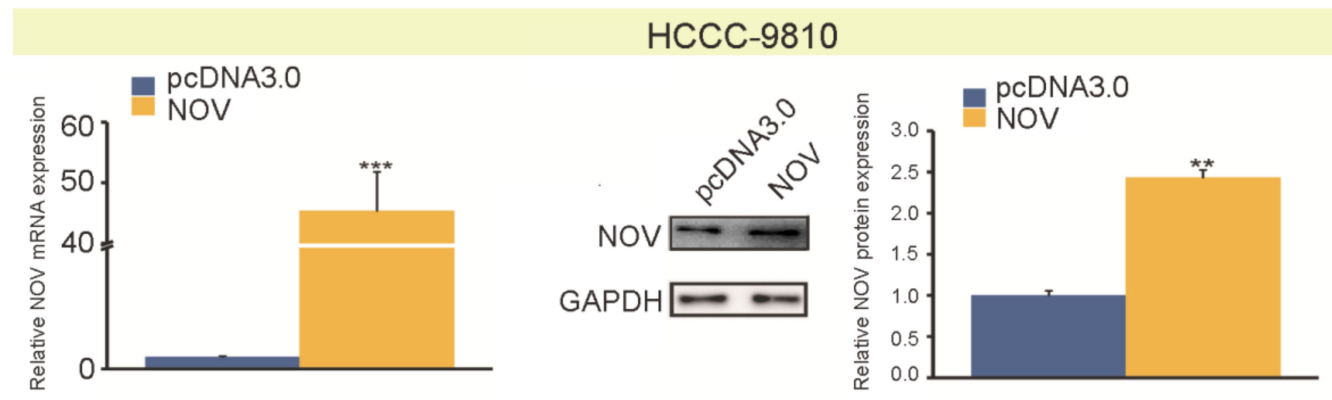

B
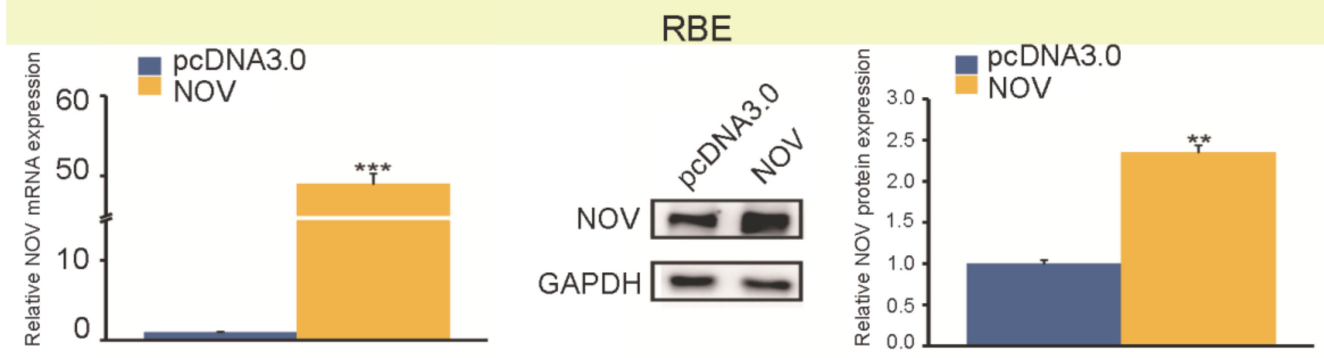

C

HCCC-9810

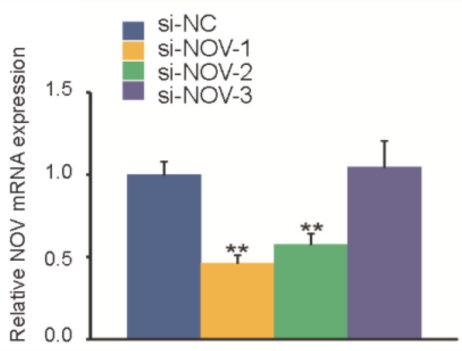

D
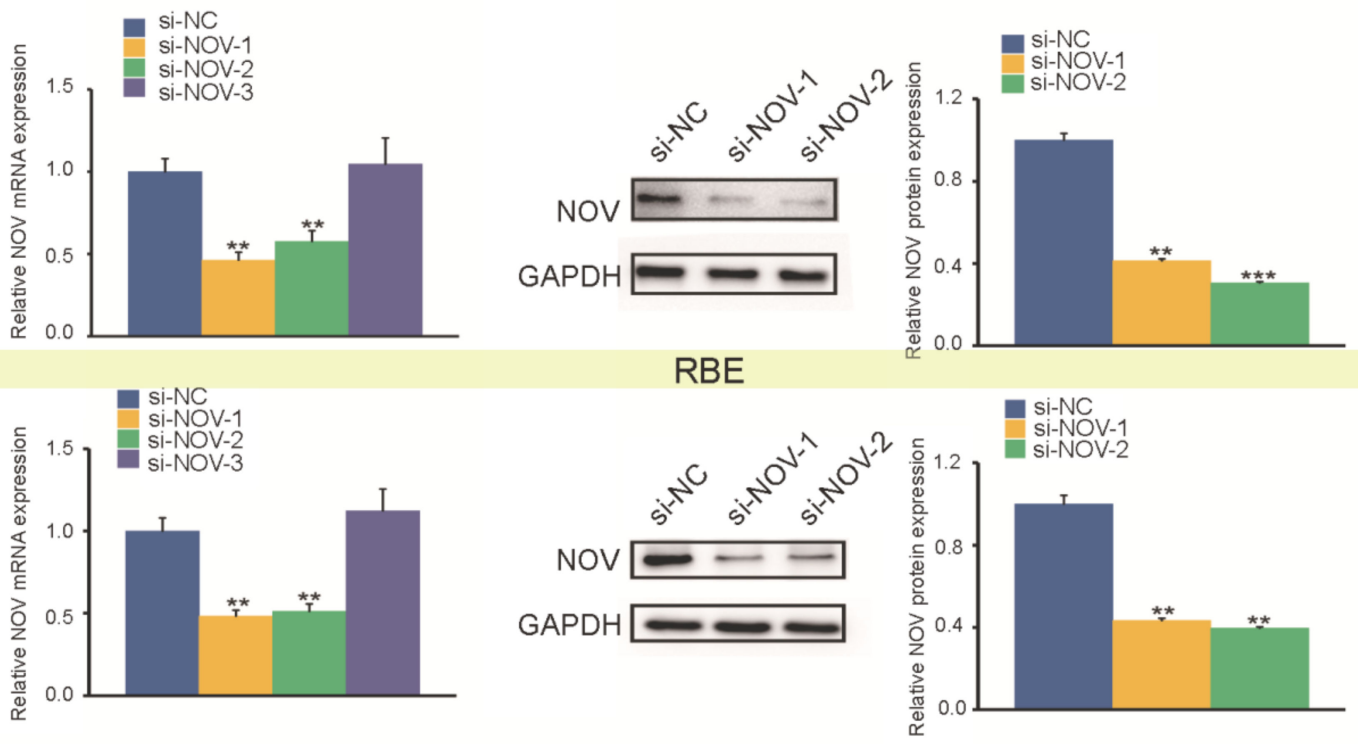

Figure 3. Overexpression and silencing of NOV in HCCC-9810 and RBE. (A). Expression efficiency of NOV mRNA (left) and protein (right) in HCCC-9810. (B) Expression efficiency of NOV mRNA (left) and protein (right) in RBE. (C) Gene silencing of NOV mRNA (left) and protein (right) in HCCC-9810. (D). Gene silencing of NOV mRNA (left) and protein (right) in RBE. All experiments are repeated three times independently, and the data are analyzed by $t$-test, ${ }^{* *}$ indicates $p<$ $0.01, * * *$ indicates $p<0.001$. 
A

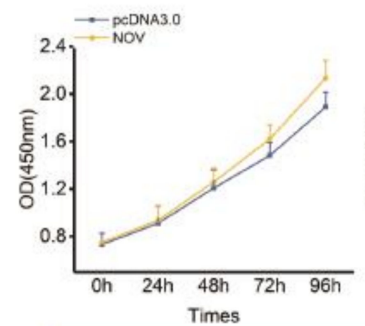

C

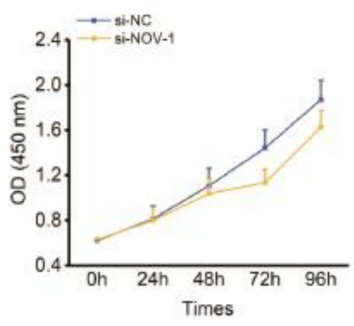

D

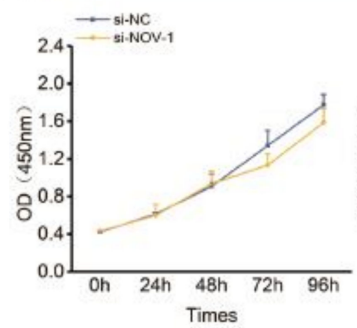

E

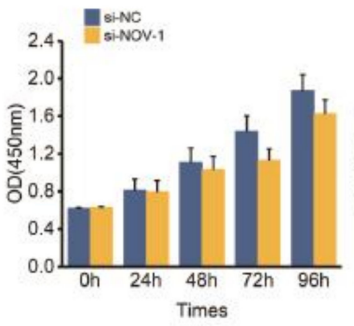

RBE
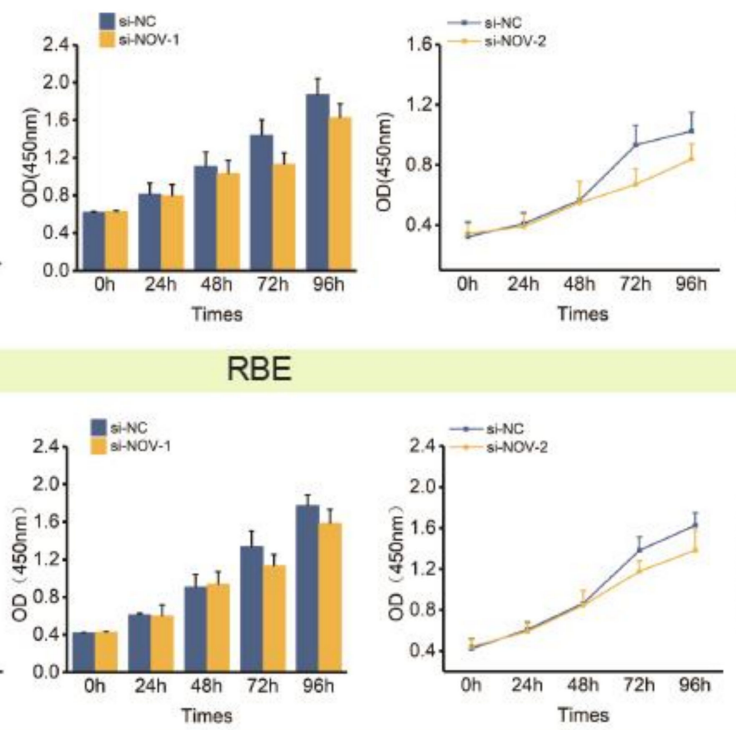

HCCC-9810

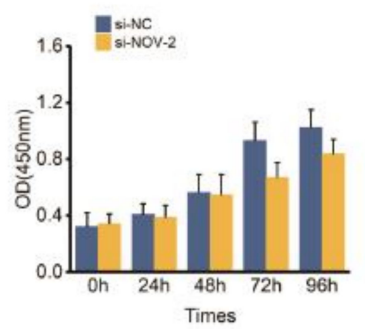

B

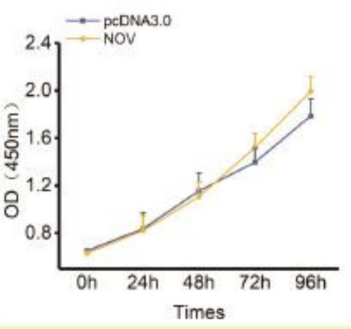

RBE
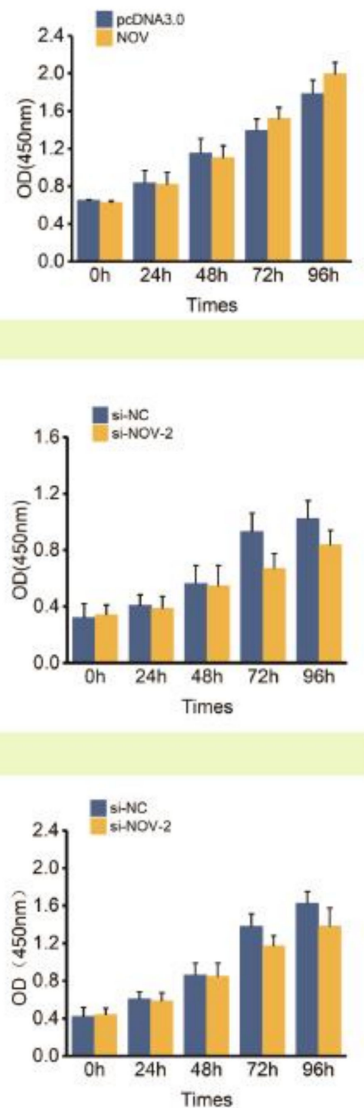
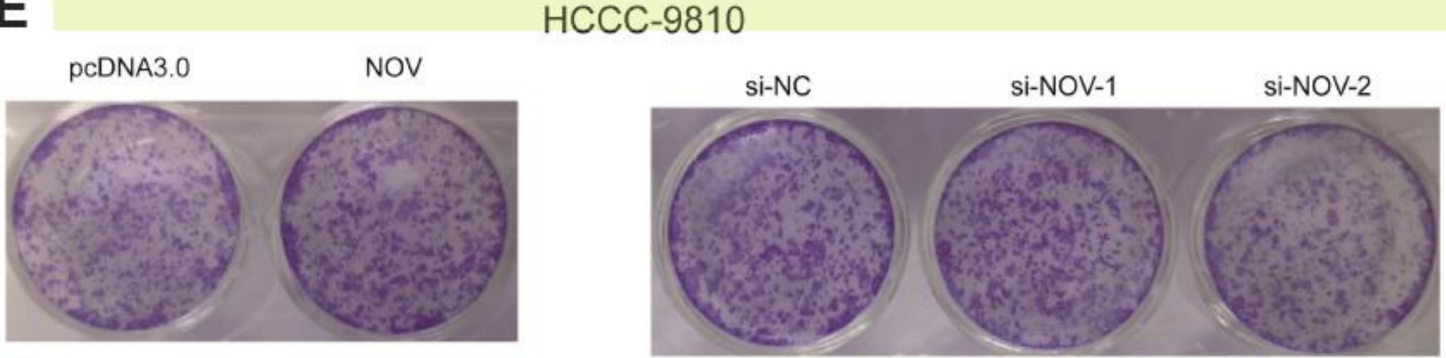

F

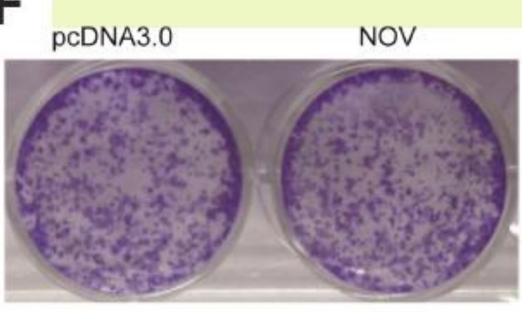

RBE

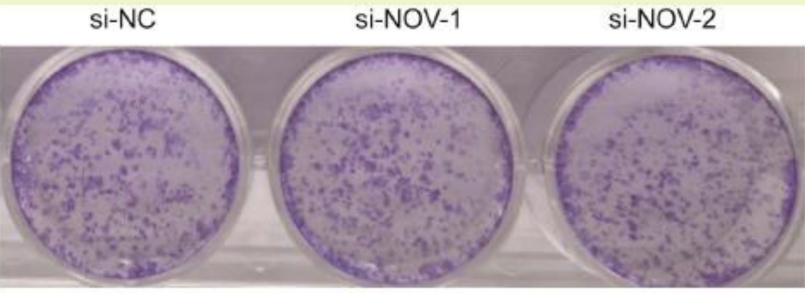

Figure 4. NOV regulates the proliferation of ICC cells. (A) The effect of NOV overexpression on cell proliferation via CCK-8 method in HCCC-9810. (B). The effect of NOV overexpression on cell proliferation via the CCK-8 method in RBE. (C) The effect of NOV silencing on cell proliferation via CCK-8 method in HCCC-9810. (D) The effect of NOV silencing on cell proliferation via the CCK-8 method in RBE. (E) The effect of NOV overexpression and silencing on cell proliferation via colony-forming assay in HCCC-9810. (F) The effect of NOV overexpression and silencing on cell proliferation via colony-forming assay in RBE. 
A
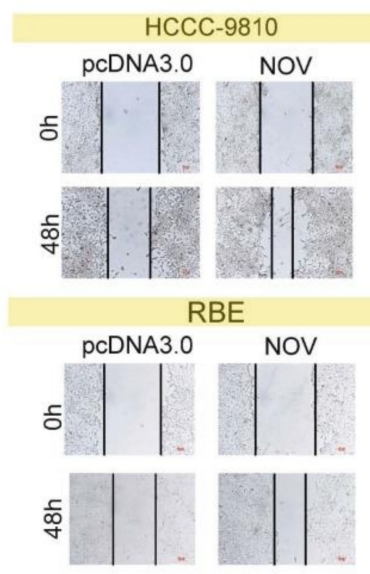

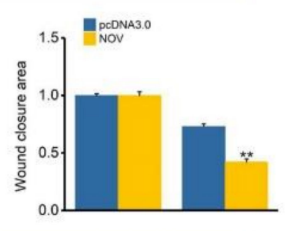

B
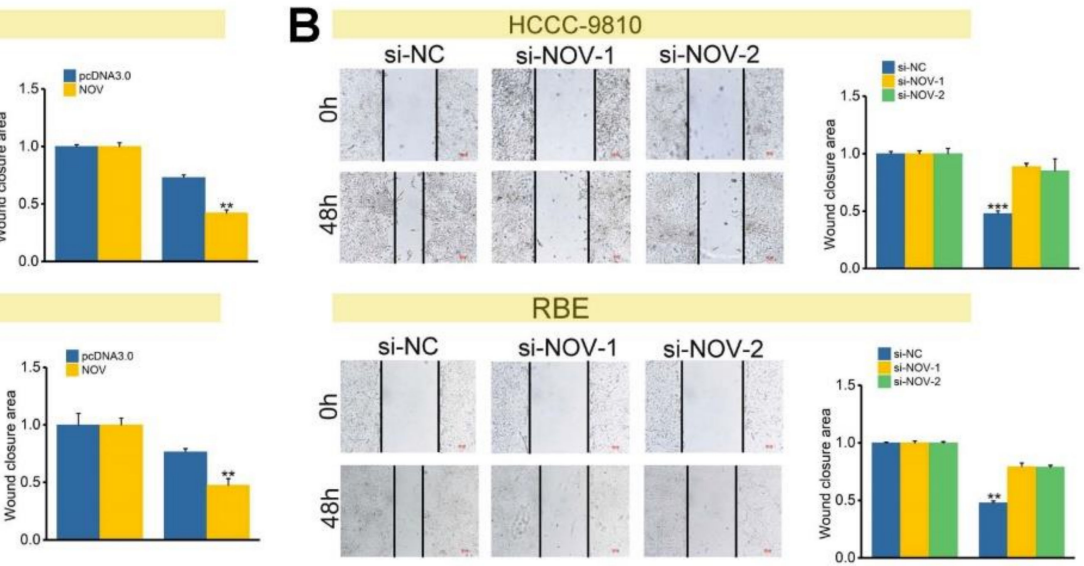

C

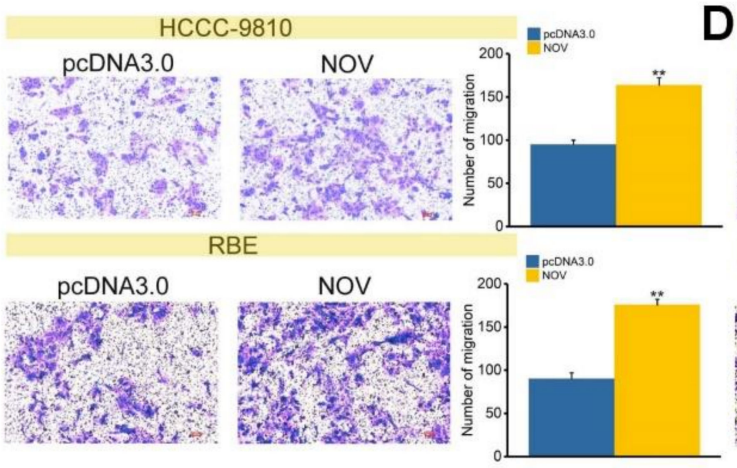

D
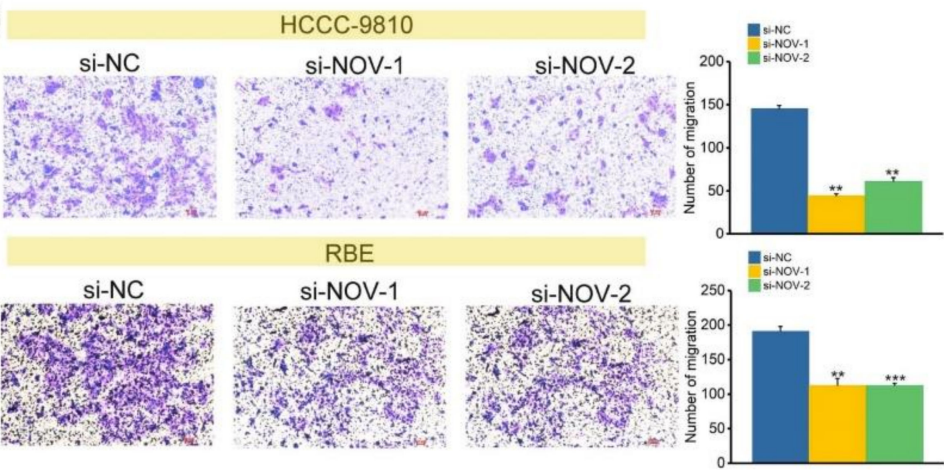

Figure 5. NOV promotes the migration of ICC cells. (A) The effect of NOV overexpression on cell migration via wound healing assay. (B) The effect of NOV silencing on cell migration via wound-healing assay. (C) The effect of NOV overexpression on cell migration via transwell migration $(100 \times)$. (D) The effect of NOV silencing on cell migration via transwell migration $(100 \times) .{ }^{* *}$ indicates $p<0.01$ and ${ }^{* * *}$ indicates $p<0.001$.

Simultaneously, NOV overexpression could promote cell migration as measured by transwell chamber assay (Figure 5C), and the number of passing through polycarbonate membrane cells was significantly higher than that in the control group at $48 \mathrm{~h}$. However, compared with the si-NC group, migration rate and the number of passing through polycarbonate membrane cells were significantly reduced si-NOV-1 and si-NOV-2 treatment (Figure 5D). These findings revealed the potential role of NOV in cell migration, and NOV can promote the migration of cholangiocarcinoma cells.

To further verify the invasive role of NOV, overexpressed plasmids were transfected into HCCC-9810 and RBE cells, and a transwell invasion assay was performed after $48 \mathrm{~h}$. Similar to migration results, overexpression of NOV could promote ICC cell invasion abilities (Figure 6A), whereas NOV silencing could impair their the invasion abilities. These findings proved confirmed that NOV could promote invasion ability of cells, indicating the potential role of NOV in cancer pathology (Figure 6B). Furthermore, Western blot analysis revealed showed that NOV overexpression could down-regulate E-cadherin, an epithelial marker protein, and simultaneously up-regulate vimentin, N-cadherin, Snail and MMP9 (Figure 6C). However, NOV silencing could up-regulate E-cadherin and down-regulate vimentin, N-cadherin, Snail and MMP9 (Figure 6D). As a result, NOV overexpression could promote the EMT process, while NOV silencing could suppress it.

\subsection{Nov Activates the Expression of Notch1 in ICC}

Activating of Notch signaling pathway has been reported to be associated with tumor metastasis [34]. Furthermore, NOV associates with the epidermal growth factor-like repeats of Notch1 by CT (C-terminal cysteine knot) domain during myoblast differentiation [35]. To determine whether NOV expression is involved in Notch signaling pathway activation 
in ICC cells, we conducted Western blot to detect Notch1 expression, an active protein in the Notch signaling pathway. The results revealed that NOV overexpression enhanced NOTCH1 expression in HCCC-9810 cells $(p<0.05)$, while down-regulated NOV significantly inhibited the expression of NOTCH1 in HCCC-9810 cells $(p<0.01)$ (Figure 7A,B). These results indicated that NOV enhanced the activity of the Notch1 signaling pathway in ICC cells.

A

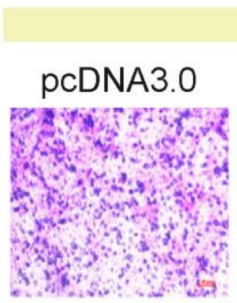
HCCC-9810
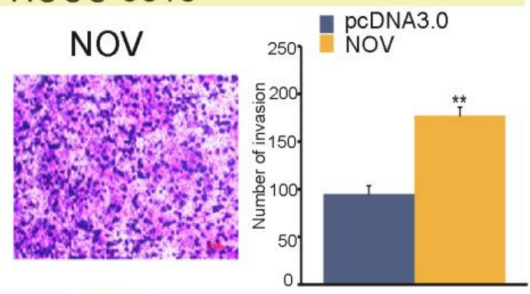

RBE

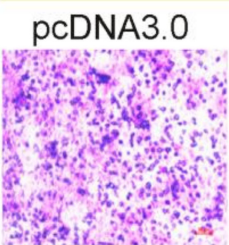

B
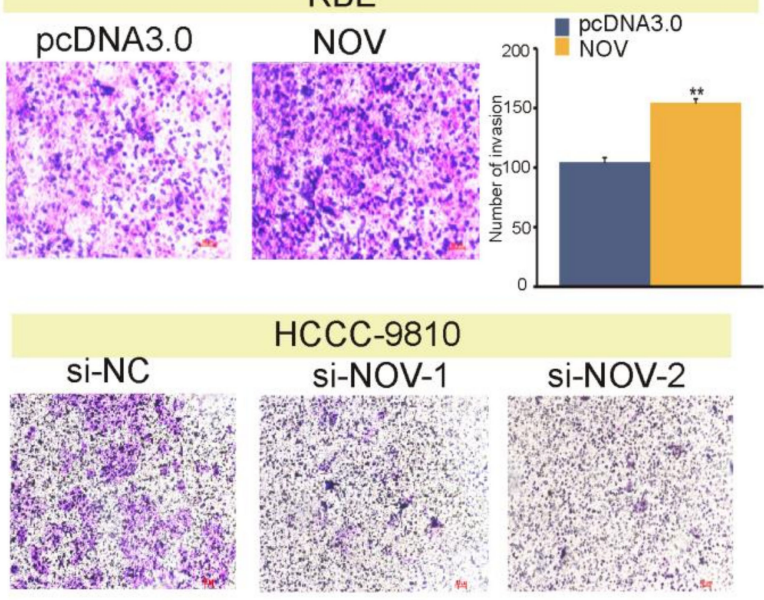

HCCC-9810
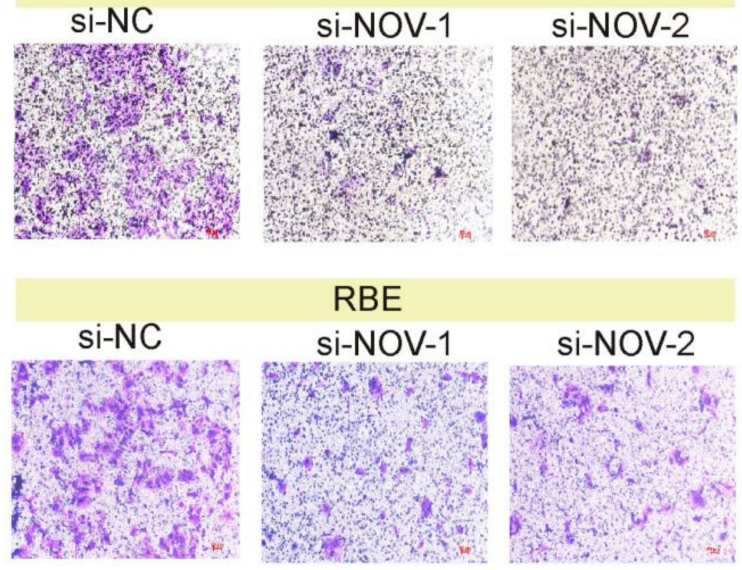

RBE

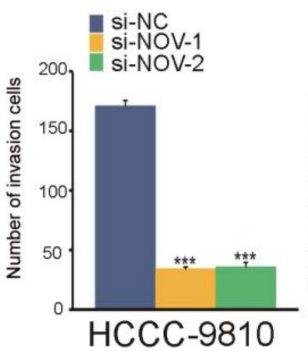

Si-NOV-1

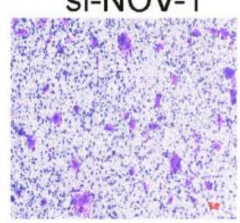

si-NOV-2
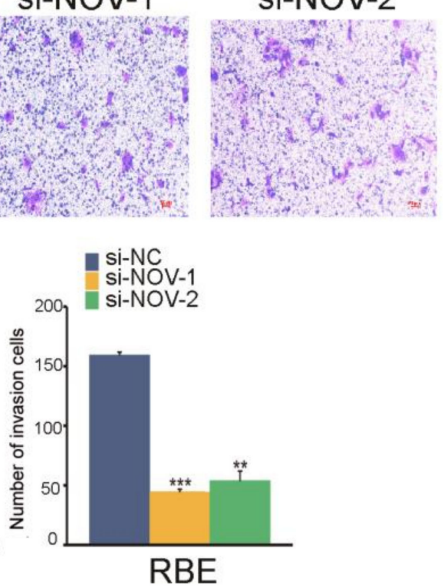

C

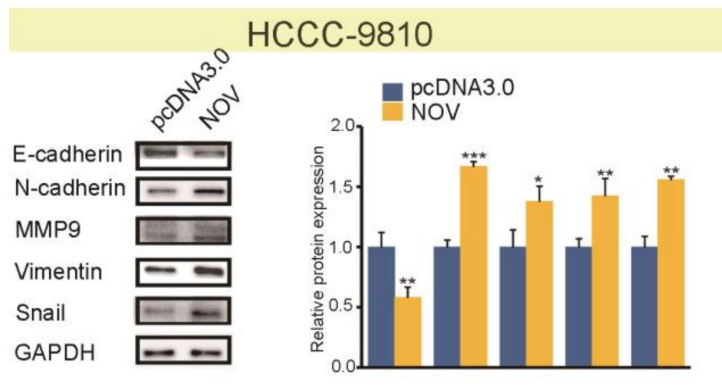

RBE

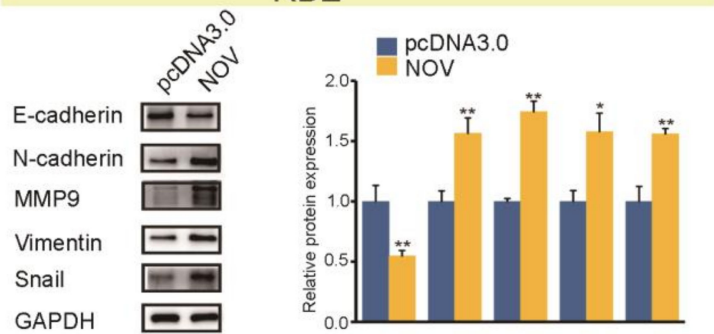

D

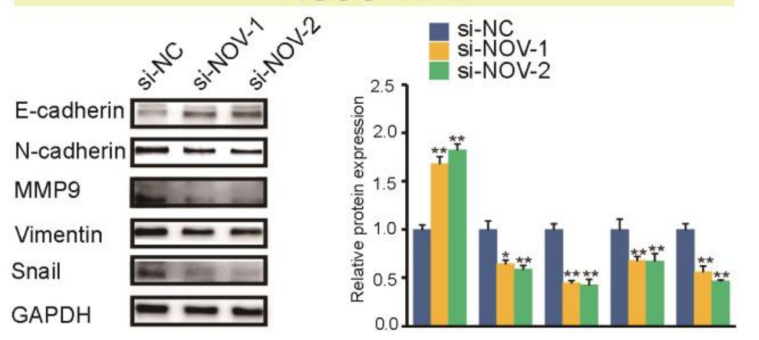

RBE

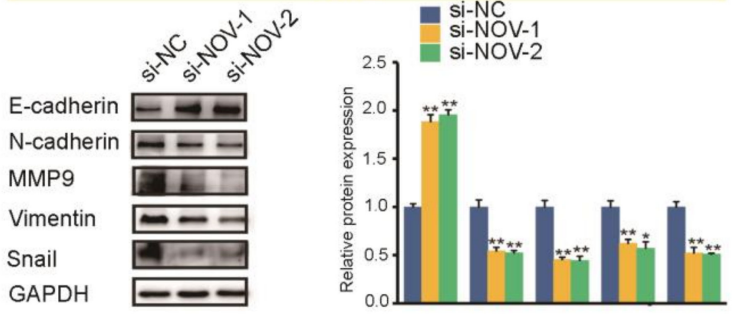

Figure 6. NOV promotes the invasion of ICC cells. (A) The effect of NOV overexpression on invasion ability $(100 \times)$. (B) The effect of NOV silencing on invasion ability $(100 \times)$. (C) The effect of NOV overexpression on EMT proteins confirmed by Western blot. (D) The effect of NOV silencing on EMT proteins confirmed by Western blot. All experiments are repeated three times independently, and the data are analyzed by $t$-test. * indicates $p<0.05,{ }^{* *}$ indicates $p<0.01$ and ${ }^{* * *}$ indicates $p<0.001$. 
A

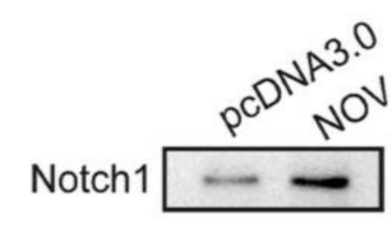

GAPDH

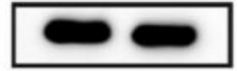

B

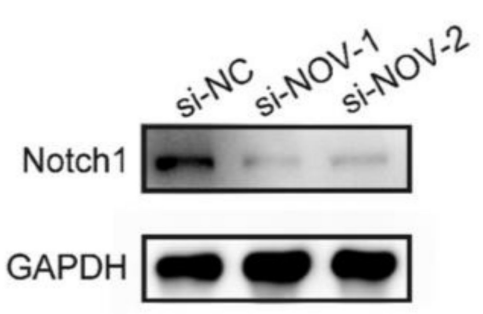

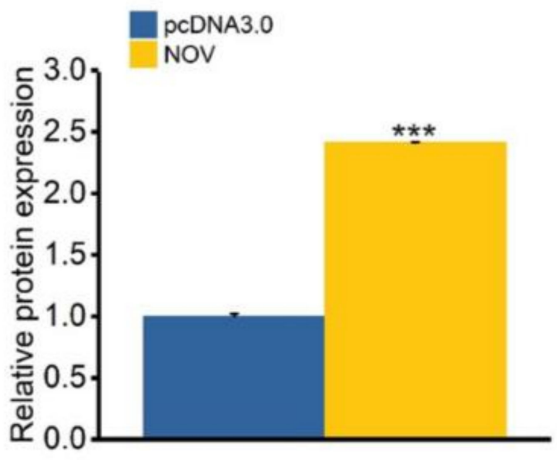

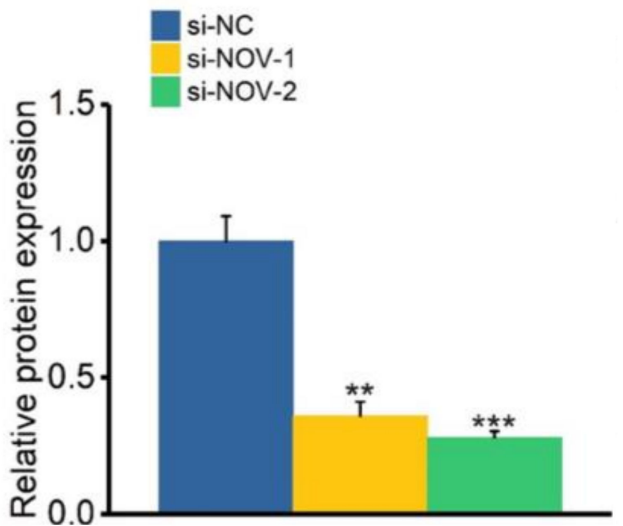

Figure 7. The effect of NOV on the Notch1 pathway. (A) The effect of NOV overexpression on Notch1 protein. (B) The effect of NOV silencing on Notch1 protein. ${ }^{* *}$ indicates $p<0.01$ and ${ }^{* * *}$ indicates $p<0.001$.

\section{6. miR-92a-3p Targets and Represses NOV Directly}

MicroRNAs (miRNA) have long been recognized as a class of important and flexible regulatory molecules [36,37], and their roles in cancer have been extensively studied [38,39]. Herein, to understand the potential role of miRNA in NOV, we queried public databases for NOV-related miRNAs. Five miRNAs were identified: miR-92a-3p, miR-30e-5p, miR455-5p, miR-197-3p and miR-186-5p. Of these, miR-92a-3p was found in three databases, while miR-30e-5p and miR-455-5p were detected in two databases (Figure 8A). We finally screened these three miRNAs based on integrative results to perform q-PCR validation, but only miR-92a-3p was down-regulated in both HCCC-9810 and RBE cells, suggesting a regulatory relationship with NOV (Figure $8 \mathrm{~B}$ ). Further, the potential regulatory correlations were also verified according to the Starbase database [26] (Figure 8C), and a significant negative correlation between miR-92a-3p and NOV could be found (Figure 8D).

Experimental validation confirmed that miR-92a-3p overexpression had no significant effect on NOV mRNA (Figure 8E), but this miRNA had a significant inhibitory effect on NOV protein (Figure $8 \mathrm{~F}$ ). To verify the direct regulatory relationship between miR-92a$3 p$ and NOV, a dual-luciferase reporter assay was performed. Based on bioinformatics analysis, a potential binding site of miR-92a-3p was located on 343-349 bp of 3' UTR of NOV (Figure 8G). Compared with the negative control group, the group with cotransfection of miR-92a-3p mimics and NOV $3^{\prime}$ UTR WT had significantly lower luciferase activity. However, no significant difference was observed between the experimental and control groups (Figure $8 \mathrm{H}$ ). 
A

\begin{tabular}{llllll} 
& & & & \\
\hline miRNA name & PITA & miRmap & miRanda & TargetScan & Sum \\
\hline hsa-miR-92a-3p & 1 & 0 & 1 & 1 & 3 \\
hsa-miR-30e-5p & 1 & 0 & 1 & 0 & 2 \\
hsa-miR-455-3p & 1 & 1 & 0 & 0 & 2 \\
hsa-miR-197-3p & 0 & 0 & 1 & 0 & 1 \\
hsa-miR-186-5p & 0 & 0 & 1 & 0 & 1 \\
\hline
\end{tabular}

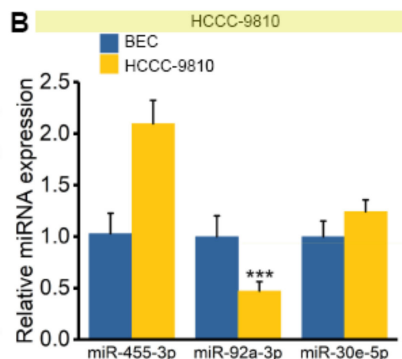

C
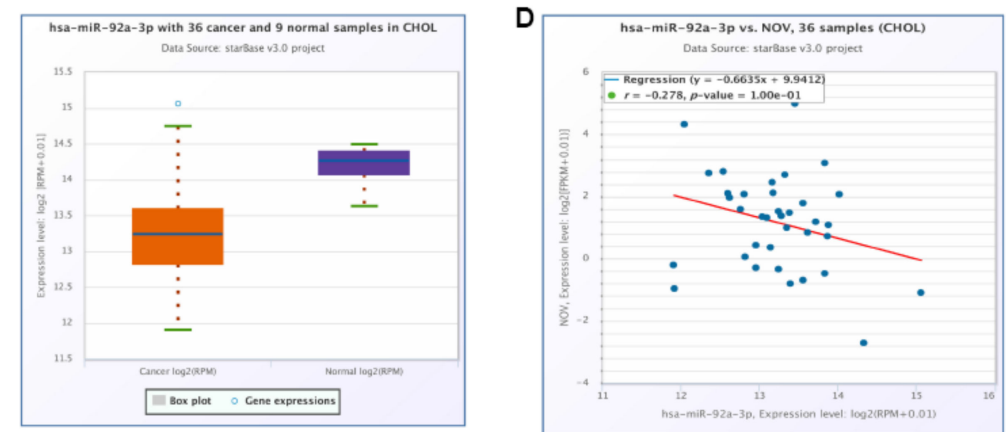

E
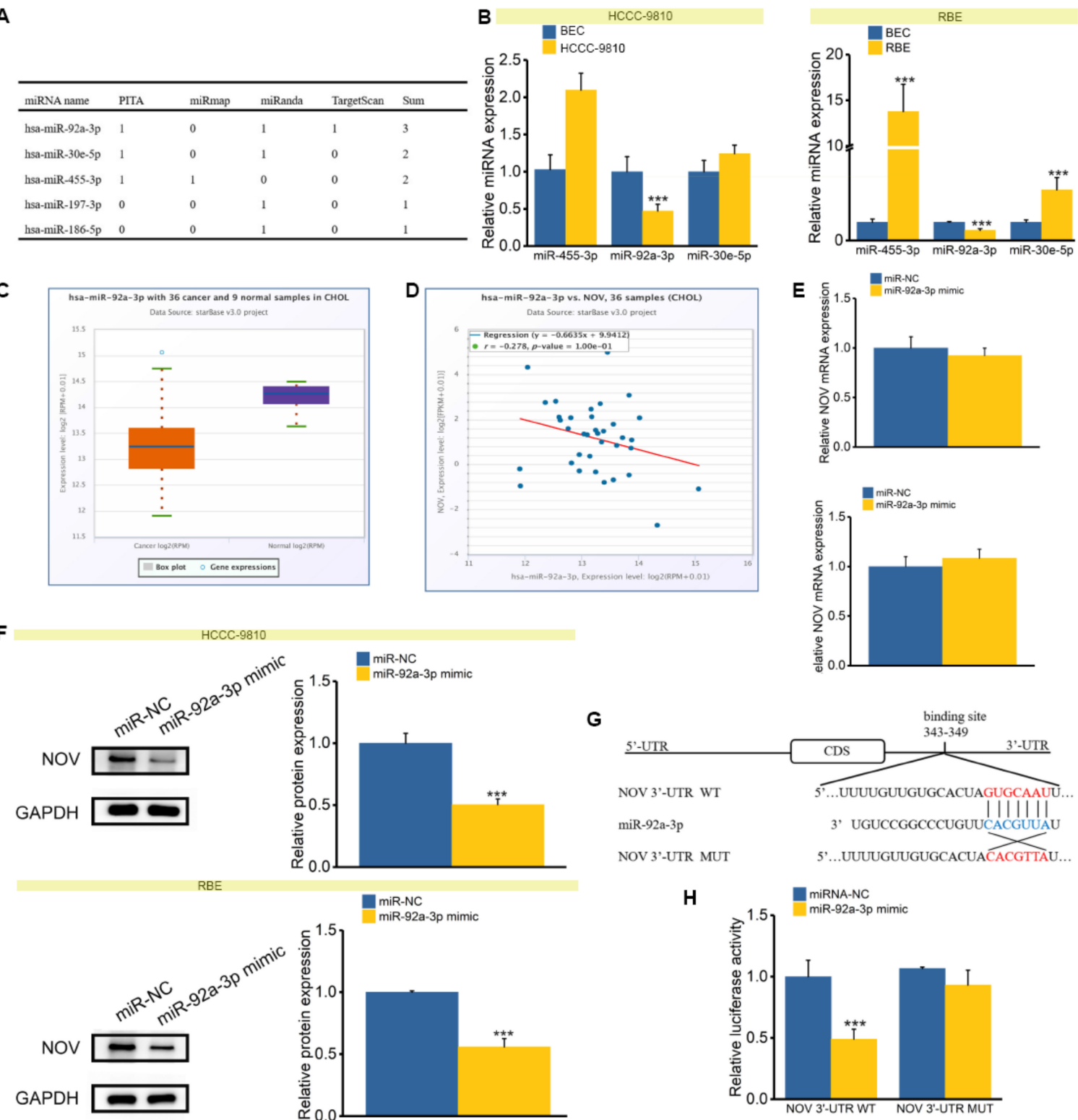

H

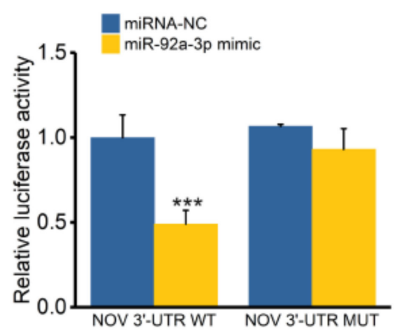

Figure 8. NOV is the direct target of miR-92a-3p. (A) Related miRNAs of NOV via different prediction methods. (B). Expression levels of miR-92a-3p, miR-30e-5p and miR-455-5p in HCCC-9810 (left) and RBE (right) cells. (C) Relative expression level of miR-92a-3p in tumor and adjacent normal samples. (D) Expression correlation of miR-92a-3p and NOV. (E) The effect of miR-92a-3p on NOV mRNA in HCCC-9810 (left) and RBE (right) cells. (F) The effect of miR-92a-3p on NOV protein in HCCC-9810 (up) and RBE (down) cells. (G). The binding site of miR-92a-3 and NOV (3'UTR WT and $3^{\prime}$ UTR MUT). (H) Luciferase activity measurements of WT and MUT after cotransfection of NOV $3^{\prime}$ UTR WT or NOV $3^{\prime}$ UTR MUT and miR-92a-3p mimic or miR-NC. ${ }^{* * *}$ indicates $p<0.001$.

\section{7. miR-92a-3p Inhibits the Migration and Invasion via Targeting NOV}

Additional experimental validation was performed to discuss whether miR-92a-3p was a crucial regulator of NOV migration and invasion. The migration effect caused by NOV overexpression was rescued by miR-92a-3p overexpression (Figure 9A). Compared with NOV overexpression, cells co-transfected with miR-92a-3p and NOV had significantly weaker invasion ability (Figure 9A-C). Moreover, miR-92a-3p down-regulated E-cadherin and also rescued the upregulation of N-cadherin, vimentin, MMP9, and Snai proteins caused by NOV overexpression (Figure 9D). Similarly, miR-92a-3p also increased expression of Notch1 caused by overexpression of NOV (Figure 9E), indicating that miR-92a-3p could regulate $\mathrm{NOV}$, and then influence cell migration and invasion via targeting NOV. 


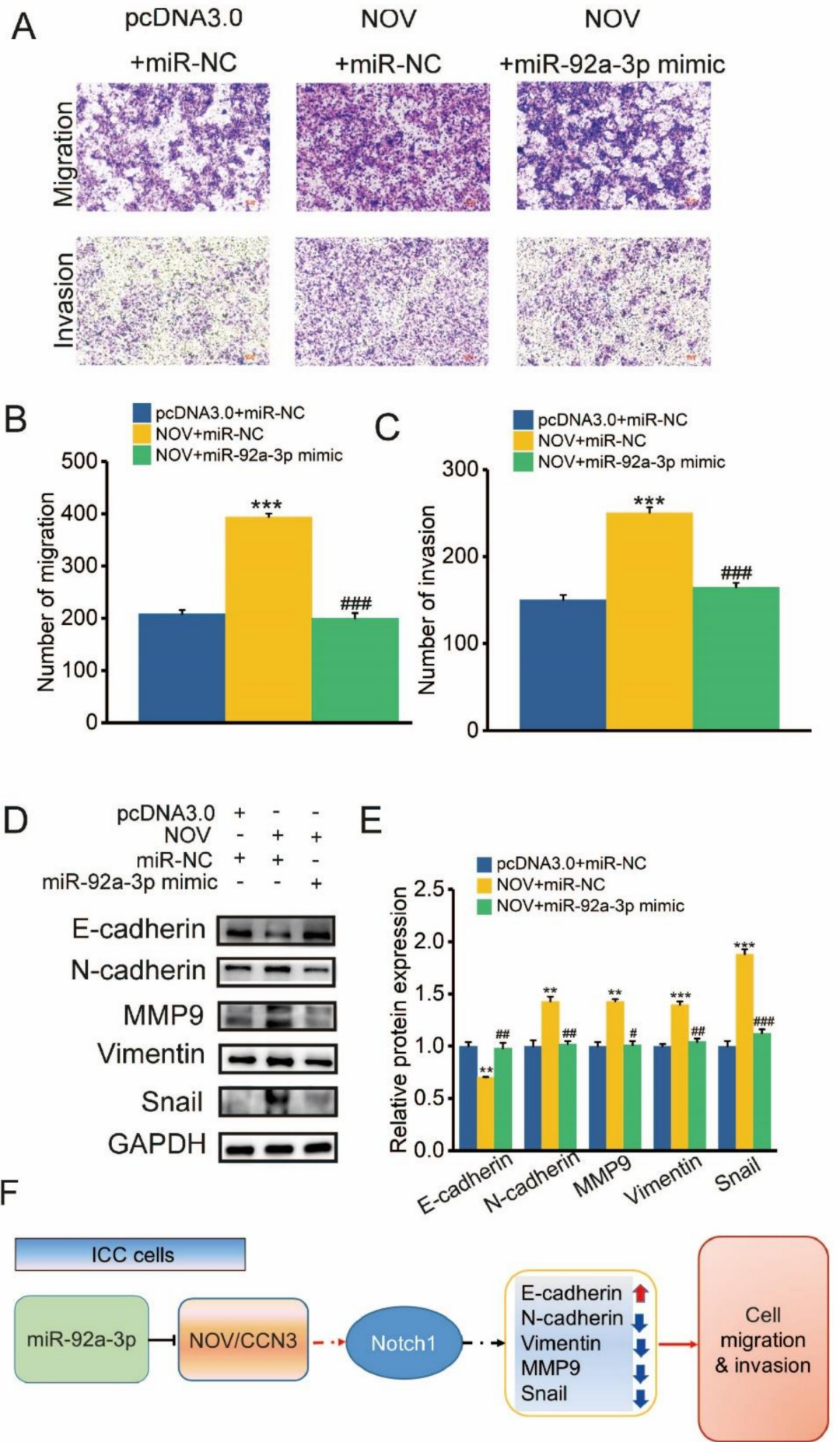

Figure 9. miR-92a-3p contributes to cell transformation and migration mediated by NOV. (A). Transwell analysis of migratory and invasive ability after transfection of miR-92a-3p mimics and NOV overexpression plasmid in HCCC-9810 cells. (B-C) The number of migratory (B) and invasive ability (C) after transfection of miR-92a-3p mimics and NOV overexpression plasmid in HCCC-9810 cells. (D-E) Expression levels of E-cadherin, N-cadherin, MMP9, vimentin and Snail after transfecting miR-92a-3p mimics and NOV overexpression plasmid in HCCC-9810 cells based on Western blot. (F) Schematic figure indicating the miR-92a-3p /NOV/Notch1 regulatory pathways and resulting biological effects in ICC. pcDNA3.0 + miR-NC vs. NOV + miR-NC: ** indicates $p<0.01$, *** indicates $p<0.001 ; \mathrm{NOV}+\mathrm{miR}-\mathrm{NC}$ vs. NOV + miR-92a-3p mimic: \# indicates $p<0.05$, \#\# indicates

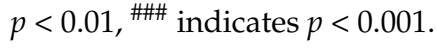




\section{Discussion}

Several members in the $\mathrm{CCN}$ gene family have been implicated in critical biological processes, most notably cancer hallmarks [40,41]. For instance, WISP1, WISP2, and WISP3 are members in the insensitivity to antigrowth signals, self-sufficiency in growth signals, tissue invasion and metastasis, and CTGF is a member in self-sufficiency in growth signals and tissue invasion and metastasis, while NOV is a member in the insensitivity to antigrowth signals. Although homologous members of the $\mathrm{CCN}$ gene family have been studied due to their roles in cancers, herein, we find that only five of them are dominantly expressed via a pan-cancer analysis. Dynamic expression patterns indicate that they may be critical in cancer occurrence and development. According to dominant expression patterns, we finally screen the NOV gene as a candidate gene in cholangiocarcinoma to further validate its potential biological role in migration and invasion. Indeed, NOV is detected as having abnormal expression patterns in only $\mathrm{CHOL}$ (significant upregulation) and BRCA (significant down-regulation) although more cancers are involved if paired analysis is performed (Figure 1). NOV has a known role in breast cancer and prostate cancer bone metastasis $[42,43]$. Compared with other homologous genes, NOV is dominantly expressed and second only to CTGF, which is stably expressed in cholangiocarcinoma. Although NOV has been implicated in a variety of biological processes, it is unclear whether it also contributes to the occurrence and development of cholangiocarcinoma. Therefore, this study aims to validate the potential biological role of NOV in cholangiocarcinoma cell lines, particularly its role in cell migration and invasion.

Numerous experimental validations have revealed that NOV contributes to cell migration and invasion. Screening the detailed regulatory mechanism is also important. Additional research has concluded that miRNAs are crucial small regulatory molecules that regulate gene expression, have been implicated in cancer pathology, and may serve as potential prognostic signatures [44-46]. Based on miRNA:mRNA interactions, we identify miR-92a-3p as a potential regulatory molecule of NOV. Both bioinformatics analysis and experimental validation have demonstrated that miR-92a-3p can regulate the expression level of NOV protein, affecting subsequent cell migration and invasion processes. miR-92a-3p has been implicated in a variety of biological processes. For instance, the HNF1A-AS1/miR-92a-3p axis affects the radiosensitivity of non-small cell lung cancer by competitively regulating the JNK pathway [47], and cell proliferation is induced in renal cell carcinoma through miR-92a-3p upregulation by targeting FBXW7 [48], miR-21-5p, and miR-92a-3p may be potential biomarkers for hepatocellular carcinoma screening [49], and circulating serum exosomal miR-92a-3p can be as a novel biomarker for early diagnosis of gastric cancer [50]. All of these findings implicate that miR-92a-3p is critical in multiple processes, and our study revealed that miR-92a-3p inhibits NOV expression via a $3^{\prime} \mathrm{UTR}$ binding site involving cell migration and invasion.

Furthermore, NOV is also a member of the Notch signaling pathway [35], which may play a potential role in mediating cell adhesion with potential crucial roles in tissue remodeling [51]. In addition, the Notch signaling pathway exhibits a role in cell proliferation, differentiation and fate determination in various tissues, and therefore contributes to cancer pathology [52-54]. Herein, to validate whether NOV mediates cell migration and invasion via the Notch signaling pathway, Western blot is used to validate potential interactions. Our results indicate that elevated NOV expression stimulates higher expression of Notch1 protein in HCCC-9810 cells while silencing NOV results in Notch1 protein down-regulation. These results suggest that NOV-Notch1 positively affects Notch signaling and promotes cell migration and invasion. Indeed, CCN3/NOV inhibits BMP-2-induced osteoblast differentiation by interacting with BMP and Notch signaling pathways [55], and NOV overexpression is associated with Notch1 extracellular domain and inhibits myoblast differentiation via the Notch signaling pathway [35]. Moreover, NOV is involved in cartilage protection via PI3K/AKT/mTOR pathway [56]. These findings also confirm the potential role of NOV, particularly as a potential drug target in future cancer treatment. 
Overall, based on bioinformatics and experimental validation, our results have revealed that miR-92a-3p-mediated NOV overexpression can promote cell migration and invasion of cholangiocarcinoma, implying its potential role in tumorigenesis. Additional studies should focus on an in-depth analysis of interactions between NOV and other molecules, including interactions with other genes with potential synthetic lethal interactions and interactions with other non-coding RNAs with complex coding-non-coding regulatory networks.

Author Contributions: Conceptualization, T.L. and L.G.; methodology, T.L., L.S. and Y.J.; software, L.J. and Y.D.; validation, L.S. and Y.J.; formal analysis, Y.J.; investigation, T.L.; resources, T.L.; data curation, T.L., L.S., Y.J. and L.J.; writing—original draft preparation, T.L.; writing—review and editing, L.G.; supervision, T.L.; project administration, T.L.; funding acquisition, T.L. and L.G. All authors have read and agreed to the published version of the manuscript.

Funding: This work was supported by the National Natural Science Foundation of China (nos. 61771251 and 62171236), the key project of social development in Jiangsu Province (no. BE2016773), the National Natural Science Foundation of Jiangsu (no. BK20171443), Sponsored by NUPTSF (no. NY220041), the Qinglan Project in Jiangsu Province, and the Priority Academic Program Development of Jiangsu Higher Education Institution (PAPD).

Institutional Review Board Statement: The study was conducted according to the guidelines of the Declaration of Helsinki, and approved by the Ethics Committee of Nanjing Normal University.

Data Availability Statement: The data and all materials are available upon request.

Conflicts of Interest: The authors declare no conflict of interest.

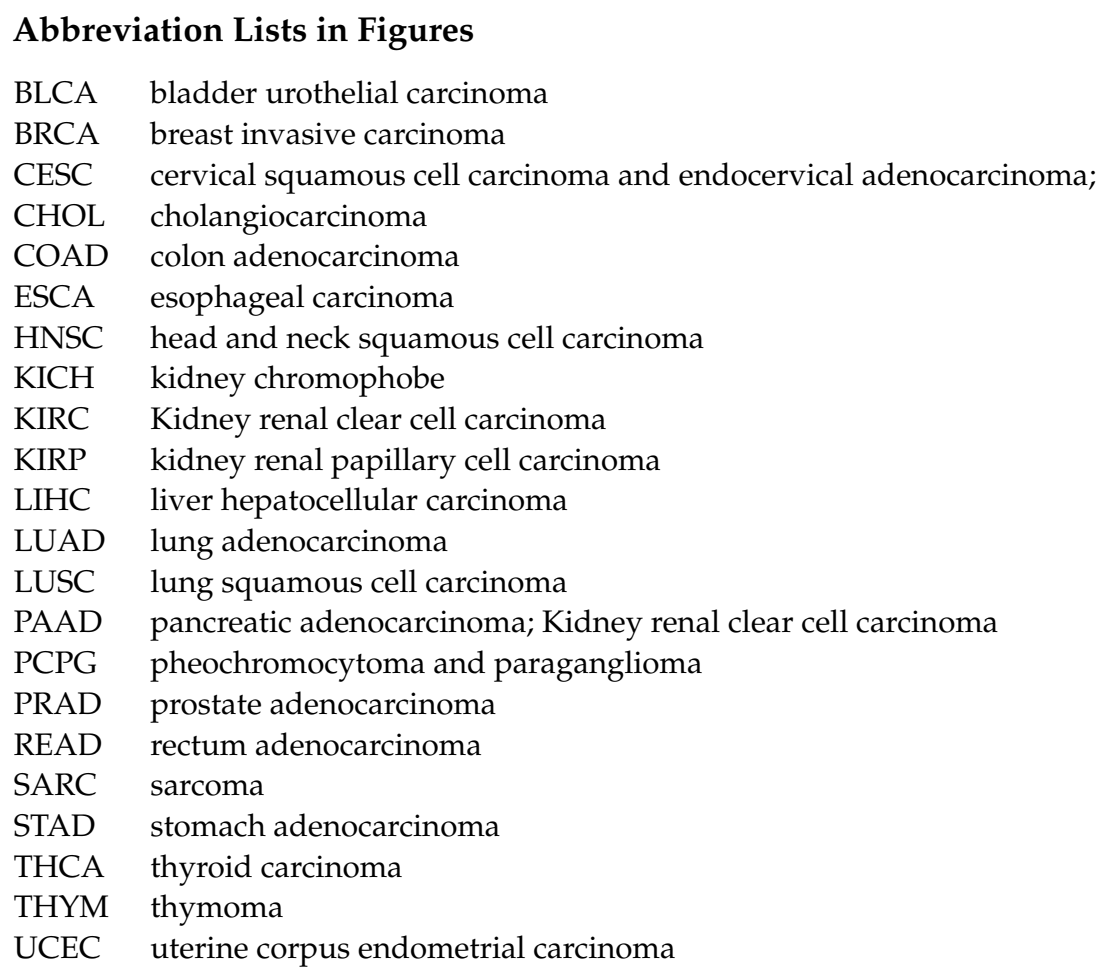

\section{References}

1. Chinchilla-López, P.; Aguilar-Olivos, N.E.; García-Gómez, J.; Hernández-Alejandro, K.K.; Chablé-Montero, F; Motola-Kuba, D.; Patel, T.; Méndez-Sánchez, N. Prevalence, Risk Factors, and Survival of Patients with Intrahepatic Cholangiocarcinoma. Ann. Hepatol. 2017, 16, 565-568. [CrossRef] [PubMed]

2. Czito, B.G.; Anscher, M.S.; Willett, C.G. Radiation therapy in the treatment of cholangiocarcinoma. Oncology 2006, 20, 873-884. [PubMed]

3. Buettner, S.; van Vugt, J.L.; IJzermans, J.N.; Groot Koerkamp, B. Intrahepatic cholangiocarcinoma: Current perspectives. OncoTargets Ther. 2017, 10, 1131-1142. [CrossRef] [PubMed] 
4. Weber, S.M.; Ribero, D.; O’Reilly, E.M.; Kokudo, N.; Miyazaki, M.; Pawlik, T.M. Intrahepatic Cholangiocarcinoma: Expert consensus statement. HPB 2015, 17, 669-680. [CrossRef] [PubMed]

5. $\quad$ Endo, I.; Gonen, M.; Yopp, A.C.; Dalal, K.M.; Zhou, Q.; Klimstra, D.; D'Angelica, M.; DeMatteo, R.P.; Fong, Y.; Schwartz, L.; et al. Intrahepatic cholangiocarcinoma: Rising frequency, improved survival, and determinants of outcome after resection. Ann. Surg. 2008, 248, 84-96. [CrossRef] [PubMed]

6. Xu, Y.-P.; Dong, Z.-N.; Zhou, Y.-Q.; Zhao, Y.-J.; Zhao, Y.; Wang, F.; Huang, X.-Y.; Guo, C.-Y. Role of eIF3C Overexpression in Predicting Prognosis of Intrahepatic Cholangiocarcinoma. Dig. Dis. Sci. 2021,1-10. [CrossRef]

7. Jing, C.-Y.; Fu, Y.-P.; Zhou, C.; Zhang, M.-X.; Yi, Y.; Huang, J.-L.; Gan, W.; Zhang, J.; Zheng, S.-S.; Zhang, B.-H.; et al. Hepatic stellate cells promote intrahepatic cholangiocarcinoma progression via NR4A2/osteopontin/Wnt signaling axis. Oncogene 2021, 40, 2910-2922. [CrossRef] [PubMed]

8. Pu, X.; Ye, Q.; Cai, J.; Yang, X.; Fu, Y.; Fan, X.; Wu, H.; Chen, J.; Qiu, Y.; Yue, S. Typing FGFR2 translocation determines the response to targeted therapy of intrahepatic cholangiocarcinomas. Cell Death Dis. 2021, 12, 256. [CrossRef]

9. Kim, S.-Y.; Lee, H.-S.; Bang, S.-M.; Han, D.-H.; Hwang, H.-K.; Choi, G.-H.; Chung, M.-J.; Kim, S.-U. Serum Dickkopf-1 in Combined with CA 19-9 as a Biomarker of Intrahepatic Cholangiocarcinoma. Cancers 2021, 13, 1828. [CrossRef]

10. Zhao, S.; Wang, J.; Qin, C. Blockade of CXCL12/CXCR4 signaling inhibits intrahepatic cholangiocarcinoma progression and metastasis via inactivation of canonical Wnt pathway. J. Exp. Clin. Cancer Res. 2014, 33, 103. [CrossRef]

11. Zhao, W.; Zhao, J.; Guo, X.; Feng, Y.; Zhang, B.; Tian, L. LncRNA MT1JP plays a protective role in intrahepatic cholangiocarcinoma by regulating miR-18a-5p/FBP1 axis. BMC Cancer 2021, 21, 142. [CrossRef] [PubMed]

12. Mancarella, S.; Serino, G.; Dituri, F.; Cigliano, A.; Ribback, S.; Wang, J.; Chen, X.; Calvisi, D.F.; Giannelli, G. Crenigacestat, a selective NOTCH1 inhibitor, reduces intrahepatic cholangiocarcinoma progression by blocking VEGFA/DLL4/MMP13 axis. Cell Death Differ. 2020, 27, 2330-2343. [CrossRef]

13. Katsube, K.-I.; Sakamoto, K.; Tamamura, Y.; Yamaguchi, A. Role of CCN, a vertebrate specific gene family, in development. Dev. Growth Differ. 2009, 51, 55-67. [CrossRef]

14. Sun, C.; Zhang, H.; Liu, X. Emerging role of CCN family proteins in fibrosis. J. Cell Physiol. 2021, 236, 4195-4206. [CrossRef]

15. Kular, L.; Pakradouni, J.; Kitabgi, P.; Laurent, M.; Martinerie, C. The CCN family: A new class of inflammation modulators? Biochimie 2011, 93, 377-388. [CrossRef]

16. Leask, A. Death of a tumor: Targeting CCN in pancreatic cancer. J. Cell Commun. Signal 2009, 3, 159-160. [CrossRef]

17. Bleau, A.M.; Planque, N.; Perbal, B. CCN proteins and cancer: Two to tango. Front. Biosci. 2005, 10, 998-1009. [CrossRef]

18. Kim, H.; Son, S.; Shin, I. Role of the CCN protein family in cancer. BMB Rep. 2018, 51, 486-492. [CrossRef]

19. Yeger, H.; Perbal, B. The CCN axis in cancer development and progression. J. Cell Commun. Signal. 2021, 1-27. [CrossRef]

20. Gardini, A.; Corti, B.; Fiorentino, M.; Altimari, A.; Ercolani, G.; Grazi, G.; Pinna, A.; Grigioni, W.; Grigioni, A.D. Expression of connective tissue growth factor is a prognostic marker for patients with intrahepatic cholangiocarcinoma. Dig. Liver Dis. 2005, 37, 269-274. [CrossRef]

21. Bonelli, P.; Tuccillo, F.M.; Borrelli, A.; Schiattarella, A.; Buonaguro, F.M. CDK/CCN and CDKI alterations for cancer prognosis and therapeutic predictivity. Biomed. Res. Int. 2014, 2014, 361020. [CrossRef] [PubMed]

22. Tong, X.; Xie, D.; O’Kelly, J.; Miller, C.W.; Muller-Tidow, C.; Koeffler, H.P. Cyr61, a Member of CCN Family, Is a Tumor Suppressor in Non-Small Cell Lung Cancer. J. Biol. Chem. 2001, 276, 47709-47714. [CrossRef]

23. Watari, H.; Xiong, Y.; Hassan, M.K.; Sakuragi, N. Cyr61, a member of ccn (connective tissue growth factor/cysteine-rich $61 /$ nephroblastoma overexpressed) family, predicts survival of patients with endometrial cancer of endometrioid subtype. Gynecol. Oncol. 2009, 112, 229-234. [CrossRef]

24. Piszczatowski, R.T.; Lents, N.H. Regulation of the CCN genes by vitamin D: A possible adjuvant therapy in the treatment of cancer and fibrosis. Cell Signal 2016, 28, 1604-1613. [CrossRef] [PubMed]

25. Colaprico, A.; Silva, T.C.; Olsen, C.; Garofano, L.; Cava, C.; Garolini, D.; Sabedot, T.S.; Malta, T.; Pagnotta, S.M.; Castiglioni, I.; et al. TCGAbiolinks: An R/Bioconductor package for integrative analysis of TCGA data. Nucleic Acids Res. 2016, 44, e71. [CrossRef]

26. Li, J.H.; Liu, S.; Zhou, H.; Qu, L.H.; Yang, J.H. starBase v2.0: Decoding miRNA-ceRNA, miRNA-ncRNA and protein-RNA interaction networks from large-scale CLIP-Seq data. Nucleic Acids Res. 2014, 42, D92-D97. [CrossRef] [PubMed]

27. Li, C.; Tang, Z.; Zhang, W.; Ye, Z.; Liu, F. GEPIA2021: Integrating multiple deconvolution-based analysis into GEPIA. Nucleic Acids Res. 2021, 49, W242-W246. [CrossRef]

28. Love, M.I.; Huber, W.; Anders, S. Moderated estimation of fold change and dispersion for RNA-seq data with DESeq2. Genome Biol. 2014, 15, 550. [CrossRef] [PubMed]

29. Vejnar, C.E.; Zdobnov, E.M. MiRmap: Comprehensive prediction of microRNA target repression strength. Nucleic Acids Res. 2012, 40, 11673-11683. [CrossRef]

30. Enright, A.J.; John, B.; Gaul, U.; Tuschl, T.; Sander, C.; Marks, D. MicroRNA targets in Drosophila. Genome Biol. 2003,5 , R1. [CrossRef]

31. Agarwal, V.; Bell, G.W.; Nam, J.W.; Bartel, D.P. Predicting effective microRNA target sites in mammalian mRNAs. eLife 2015, 4, e05005. [CrossRef] [PubMed]

32. Zhang, Y.; Wang, C. Nephroblastoma overexpressed (NOV/CCN3) gene: A paired-domain-specific PAX3-FKHR transcription target that promotes survival and motility in alveolar rhabdomyosarcoma cells. Oncogene 2011, 30, 3549-3562. [CrossRef] [PubMed] 
33. Wu, L.; Runkle, C.; Jin, H.; Li, J.; Yang, X.; Kuzel, T.; Lee, C.; Yu, J. CCN3/NOV gene expression in human prostate cancer is directly suppressed by the androgen receptor. Oncogene 2014, 33, 504-513. [CrossRef]

34. Bailey, J.M.; Singh, P.K.; Hollingsworth, M.A. Cancer metastasis facilitated by developmental pathways: Sonic hedgehog, Notch, and bone morphogenic proteins. J. Cell Biochem. 2007, 102, 829-839. [CrossRef]

35. Sakamoto, K.; Yamaguchi, S.; Ando, R.; Miyawaki, A.; Kabasawa, Y.; Takagi, M.; Li, C.L.; Perbal, B.; Katsube, K.-I. The Nephroblastoma Overexpressed Gene (NOV/ccn3) Protein Associates with Notch1 Extracellular Domain and Inhibits Myoblast Differentiation via Notch Signaling Pathway. J. Biol. Chem. 2002, 277, 29399-29405. [CrossRef]

36. Eulalio, A.; Huntzinger, E.; Izaurralde, E. Getting to the root of miRNA-mediated gene silencing. Cell 2008, 132, 9-14. [CrossRef]

37. Benfey, P.N. Molecular biology: microRNA is here to stay. Nature 2003, 425, 244-245. [CrossRef]

38. Lu, J.; Getz, G.; Miska, E.; Alvarez-Saavedra, E.; Lamb, J.; Peck, D.; Sweet-Cordero, A.; Ebert, B.L.; Mak, R.H.; Ferrando, A.A.; et al. MicroRNA expression profiles classify human cancers. Nature 2005, 435, 834-838. [CrossRef]

39. Gabisonia, K.; Prosdocimo, G.; Aquaro, G.D.; Carlucci, L.; Zentilin, L.; Secco, I.; Ali, H.; Braga, L.; Gorgodze, N.; Bernini, F.; et al. MicroRNA therapy stimulates uncontrolled cardiac repair after myocardial infarction in pigs. Nature 2019, 569, 418-422. [CrossRef]

40. Hanahan, D.; Weinberg, R.A. Hallmarks of cancer: The next generation. Cell 2011, 144, 646-674. [CrossRef]

41. Senga, S.S.; Grose, R.P. Hallmarks of cancer-the new testament. Open Biol. 2021, 11, 200358. [CrossRef] [PubMed]

42. Chen, P.C.; Cheng, H.C.; Tang, C.H. CCN3 promotes prostate cancer bone metastasis by modulating the tumor-bone microenvironment through RANKL-dependent pathway. Carcinogenesis 2013, 34, 1669-1679. [CrossRef] [PubMed]

43. Chen, P.C.; Lin, T.H.; Cheng, H.C.; Tang, C.H. CCN3 increases cell motility and ICAM-1 expression in prostate cancer cells. Carcinogenesis 2012, 33, 937-945. [CrossRef]

44. Zhao, Y.; Xu, L.; Wang, X.; Niu, S.; Chen, H.; Li, C. A novel prognostic mRNA/miRNA signature for esophageal cancer and its immune landscape in cancer progression. Mol. Oncol. 2021, 15, 1088-1109. [CrossRef]

45. Chen, S.; Gao, C.; Yu, T.; Qu, Y.; Xiao, G.G.; Huang, Z. Bioinformatics Analysis of a Prognostic miRNA Signature and Potential Key Genes in Pancreatic Cancer. Front. Oncol. 2021, 11, 641289. [CrossRef] [PubMed]

46. Cui, Y.; Lyu, X.; Ding, L.; Ke, L.; Yang, D.; Pirouz, M.; Qi, Y.; Ong, J.; Gao, G.; Du, P.; et al. Global miRNA dosage control of embryonic germ layer specification. Nature 2021, 593, 602-606. [CrossRef]

47. Wang, Z.; Liu, L.; Du, Y.; Mi, Y.; Wang, L. The HNF1A-AS1/miR-92a-3p axis affects the radiosensitivity of non-small cell lung cancer by competitively regulating the JNK pathway. Cell Biol. Toxicol. 2021, 37, 715-729. [CrossRef]

48. Zeng, R.; Huang, J.; Sun, Y.; Luo, J. Cell proliferation is induced in renal cell carcinoma through miR-92a-3p upregulation by targeting FBXW7. Oncol. Lett. 2020, 19, 3258-3268. [CrossRef] [PubMed]

49. Sorop, A.; Iacob, R.; Iacob, S.; Constantinescu, D.; Chitoiu, L.; Fertig, T.E.; Dinischiotu, A.; Chivu-Economescu, M.; Bacalbasa, N.; Savu, L.; et al. Plasma Small Extracellular Vesicles Derived miR-21-5p and miR-92a-3p as Potential Biomarkers for Hepatocellular Carcinoma Screening. Front. Genet. 2020, 11, 712. [CrossRef]

50. Lu, X.; Lu, J.; Wang, S.; Zhang, Y.; Ding, Y.; Shen, X.; Jing, R.; Ju, S.; Chen, H.; Cong, H. Circulating serum exosomal miR-92a-3p as a novel biomarker for early diagnosis of gastric cancer. Future Oncol. 2021, 17, 907-919. [CrossRef]

51. Dill, M.T.; Rothweiler, S.; Djonov, V.; Hlushchuk, R.; Tornillo, L.; Terracciano, L.; Meili-Butz, S.; Radtke, F.; Heim, M.H.; Semela, D. Disruption of Notch1 induces vascular remodeling, intussusceptive angiogenesis, and angiosarcomas in livers of mice. Gastroenterology 2012, 142, 967-977. [CrossRef]

52. Anusewicz, D.; Orzechowska, M.; Bednarek, A.K. Notch Signaling Pathway in Cancer-Review with Bioinformatic Analysis. Cancers 2021, 13, 768. [CrossRef] [PubMed]

53. Fasoulakis, Z.; Daskalakis, G.; Theodora, M.; Antsaklis, P.; Sindos, M.; Diakosavvas, M.; Angelou, K.; Loutradis, D.; Kontomanolis, E.N. The Relevance of Notch Signaling in Cancer Progression. Adv. Exp. Med. Biol. 2021, 1287, 169-181. [CrossRef]

54. Jain, C.K.; Bhargava, S.; Jain, I.; Varshney, S. Targeting Notch Pathway in Cancer Diagnostics and Therapeutics: An Emerging Approach. Recent Patents Anti-Cancer Drug Discov. 2021, 16, 1. [CrossRef] [PubMed]

55. Minamizato, T.; Sakamoto, K.; Liu, T.; Kokubo, H.; Katsube, K.-I.; Perbal, B.; Nakamura, S.; Yamaguchi, A. CCN3/NOV inhibits BMP-2-induced osteoblast differentiation by interacting with BMP and Notch signaling pathways. Biochem. Biophys. Res. Commun. 2007, 354, 567-573. [CrossRef] [PubMed]

56. Huang, X.; Ni, B.; Mao, Z.; Xi, Y.; Chu, X.; Zhang, R.; Ma, X.; You, H. NOV/CCN3 induces cartilage protection by inhibiting PI3K/AKT/mTOR pathway. J. Cell. Mol. Med. 2019, 23, 7525-7534. [CrossRef] [PubMed] 